\title{
Current developments in the use of transcatheter aortic valve implantation in high-risk patients
}

This article was published in the following Dove Press journal:

Research Reports in Clinical Cardiology

23 September 2014

Number of times this article has been viewed

\author{
Vijaya K Pera' \\ Sanjeevan Pasupati \\ 'Cardiovascular Division, University \\ of Minnesota, Minneapolis, MN, USA \\ ${ }^{2}$ Department of Cardiology, Waikato \\ Hospital, Hamilton, New Zealand
}

\begin{abstract}
Transcatheter aortic valve implantation (TAVI) has revolutionized the landscape of interventional cardiology. Since its introduction in 2002 by Cribier, this novel technology has developed remarkably over time, with new generations of devices, a reduction in profile sizes, and new access routes, allowing for safer and more efficacious procedures. Innovation brings new solutions as well as new challenges. The initial promising results have not only created high expectations but also a need to address the shortcomings of this procedure. Improved understanding of the potential complications associated with TAVI might help improve outcomes and broaden the application of this rapidly evolving, innovative therapy. This paper summarizes the current evidence, discusses the limitations of current TAVI technology, and highlights future perspectives.
\end{abstract}

Keywords: aortic stenosis, transcatheter aortic valve implantation

\section{Introduction}

Aortic stenosis is the most common valvular heart disease in adults ${ }^{1}$ and primarily presents as calcific aortic stenosis due to degeneration of the valve in the elderly population, with an estimated incidence of $2 \%-7 \%$ in those older than 65 years. $^{2}$ Symptomatic severe aortic stenosis has a poor prognosis when treated medically and inevitably leads to functional deterioration, heart failure, and death. ${ }^{3}$ Surgical aortic valve replacement (SAVR) has long been the standard of care for symptomatic aortic stenosis, but approximately $30 \%$ of patients do not undergo SAVR due to various comorbidities and increased operative risk. ${ }^{1,4}$ Cribier pioneered the first transcatheter aortic valve implantation (TAVI) in an inoperable patient in 2002 using a balloon-expandable aortic valve prosthesis via a transseptal antegrade approach. ${ }^{5} \mathrm{~A}$ first-in-man retrograde implantation of a self-expanding prosthesis (CoreValve ${ }^{\circledR}$, Medtronic CoreValve LLC, Irvine, CA, USA) was performed in 2005 with the aid of extracorporeal circulation. ${ }^{6}$ Based on registry data, both the CoreValve and Edwards SAPIENTM valve (Edwards Lifesciences, Irvine, CA, USA) obtained CE marking in 2007, which opened up sales in European countries for surgically high-risk and inoperable patients.

Following the first randomized study, ie, PARTNER I (Placement of Aortic Transcatheter Valves), ${ }^{7,8}$ the US Food and Drug Administration approved the Edwards valve for use in inoperable patients with symptomatic severe aortic stenosis in 2011 and extremely high surgical risk patients in 2012. CoreValve has also recently been approved for inoperable patients since the presentation of the US CoreValve clinical study in an extreme risk population at the 2013 Transcatheter Cardiovascular Therapeutics meeting in San Francisco, CA, USA. ${ }^{19}$ The growth in use of TAVI has been exponential,
Correspondence: Sanjeevan Pasupati Department of Cardiology, Waikato Hospital, Private Bag 3200, Hamilton 3240, New Zealand Email drspasupati@gmail.com 
with $>50,000$ procedures having been performed in over 40 countries worldwide in the last 11 years. With this widespread implementation of TAVI, there is now a great need to understand and overcome the limitations of TAVI and find answers to unresolved questions, including who should receive it? What are the technological improvements that are required to reduce the complications and to optimize the outcomes following TAVI? In this paper, we review the historical data on TAVI in high-risk patients, as well as the complications and evolution of transcatheter valves, and discuss procedural and technical considerations in high-risk patients along with future perspectives.

\section{Historical review of TAVI}

Following the first-in-man experience of TAVI in 2002 reported by Cribier, several feasibility studies were performed using both the balloon-expandable Edwards valve (Edwards Lifesciences) and the self-expandable CoreValve ReValving system (Medtronic CoreValve LLC). ${ }^{9-13}$ These early studies showed that TAVI could be performed in high-risk patients via both antegrade transapical and retrograde transfemoral routes with a high procedural success rate and a 30-day mortality of approximately $10 \%-15 \%$.

\section{Randomized controlled studies Edwards SAPIEN valve}

Three randomized controlled trials have assessed the efficacy of TAVI in different populations. The landmark PARTNER study incorporated two parallel, prospective, multicenter, randomized, active-treatment controlled clinical trials. In the PARTNER I study cohort B, 358 patients with severe symptomatic aortic stenosis, whom surgeons considered not suitable for SAVR, were randomized to either standard therapy (medical therapy including balloon aortic valvuloplasty) or transfemoral TAVI using the Edwards SAPIEN valve. ${ }^{7}$ At one year, the rate of death from any cause (Kaplan-Meier analysis) was $30.7 \%$ with TAVI, as compared with $50.7 \%$ with standard therapy (hazard ratio 0.55 for TAVI; $95 \%$ confidence interval [CI] $0.40-0.74 ; P<0.001)$. TAVI was associated with fewer cardiac symptoms (New York Heart Association functional class III or IV, $25.2 \%$ versus $58.0 \%, P<0.001$ ) and lower rehospitalization rates $(22.3 \%$ versus $44.1 \%$, $P<0.001)$. Among patients who underwent TAVI, the mean aortic valve area increased from $0.6 \pm 0.2 \mathrm{~cm}^{2}$ at baseline to $1.5 \pm 0.5 \mathrm{~cm}^{2}$ at 30 days $(P<0.001)$, and the mean aortic valve gradient decreased from $44.5 \pm 15.7 \mathrm{mmHg}$ to $11.1 \pm 6.9 \mathrm{mmHg}$ $(P<0.001)$. At the one-year follow-up assessment, the improvement in aortic valve area and mean gradient was maintained. The rate of death at 2 years was $43.3 \%$ in the TAVI group and $68.0 \%$ in the standard therapy group $(P<0.001)$, and the corresponding rates of cardiac death were $31.0 \%$ and $62.4 \%$, respectively $(P<0.001) .{ }^{14}$ At 2 years, the rate of rehospitalization was $35.0 \%$ in the TAVI group and $72.5 \%$ in the standard therapy group $(P<0.001)$.

In the PARTNER I study cohort A, 699 high-risk patients with severe aortic stenosis were randomized to undergo either TAVI (via a transfemoral or transapical approach) or SAVR. ${ }^{8}$ The all-cause mortality at one year in the TAVI arm was noninferior to that in the SAVR arm $(24.2 \%$ versus $26.8 \%, P=0.001$ for noninferiority). There was no significant difference in rehospitalization rates $(18.2 \%$ versus $15.5 \%)$ or New York Heart Association functional class between the two arms at one year. At 2 years, all-cause mortality was similar in the two groups by Kaplan-Meier analysis $(33.9 \%$ in the TAVI group versus $35.0 \%$ in the SAVR group, $P=0.78) .{ }^{15}$ At one year, TAVI was slightly superior to SAVR with respect to the mean aortic valve gradient $(10.1 \pm 3.9 \mathrm{mmHg}$ versus $11.4 \pm 5.3 \mathrm{mmHg}, P=0.005)$ and mean valve area $\left(1.59 \pm 0.47 \mathrm{~cm}^{2}\right.$ versus $\left.1.44 \pm 0.47 \mathrm{~cm}^{2}, P=0.002\right)$, but there was no such difference between the two groups at the 2-year follow-up. ${ }^{16}$ At one year, the cost analysis was similar for TAVI and SAVR. ${ }^{17}$ However, access site-based stratification showed transfemoral access to be less costly and with better quality-adjusted life years compared with SAVR, indicating an economically attractive option. Transapical access proved to be substantially more costly with fewer quality-adjusted life years compared with SAVR, indicating a loss.

Makkar et al recently presented the 3-year follow-up results of the PARTNER trial at the 2013 Transcatheter Cardiovascular Therapeutics meeting (as yet not published). In cohort B (inoperable) patients, TAVI continues to be superior to medical therapy, with an all-cause mortality and cardiac mortality of $54.1 \%$ versus $80.9 \%$ and $41.4 \%$ versus $74.5 \%$, respectively $(P<0.0001)$. All-cause mortality of TAVI patients in PARTNER cohort A (high-risk) was comparable with that of SAVR at the 3-year follow-up (44.2\% versus $44.8 \%$ ). STACCATO (A Prospective, Randomised Trial of Transapical Transcatheter Aortic Valve Implantation versus Surgical Aortic Valve Replacement in Operable Elderly Patients with Aortic Stenosis) randomized low-risk patients aged $>75$ years to transapical TAVI or SAVR but was prematurely terminated due to a high event rate in the TAVI arm. ${ }^{18}$

\section{Medtronic CoreValve}

Medtronic CoreValve LLC have completed their US pivotal trial in both high-risk (against SAVR) and extreme-risk 
(against a prespecified objective performance goal) cohorts. Popma et al recently published the results of the CoreValve Extreme Risk Iliofemoral Study, ${ }^{19}$ which evaluated the safety and efficacy of the CoreValve System in 471 patients deemed extreme risk for surgical aortic valve replacement (predicted risk of operative mortality or serious irreversible morbidity of $\geq 50 \%$ at 30 days). At one-year follow-up, the rate of death or major stroke was $25.5 \%$ against a prespecified objective performance goal of $43 \%(P<0.0001)$, with an all-cause mortality and cardiovascular mortality of $24.0 \%$ and $17.9 \%$, respectively. Adams et al recently presented the landmark US CoreValve trial results in high-risk patients (estimated risk of death within 30 days after surgery $\geq 15 \%$ and risk of death or irreversible complications within 30 days after surgery $<50 \%) .{ }^{20}$ In the as-treated analysis, the rate of death from any cause at one year was significantly lower in the TAVI group than in the surgical group $(14.2 \%$ versus $19.1 \% ; P<0.001$ for noninferiority; $P=0.04$ for superiority). The results were similar in the intention-to-treat analysis. Using a hierarchical testing procedure, TAVI was noninferior with respect to echocardiographic indices of valve stenosis, functional status, and quality of life. Exploratory analyses suggested a reduction in the rate of major adverse cardiac and cerebrovascular events $(20.4 \%$ for TAVI versus $27.2 \%$ for SAVR, $P=0.03$ ) and no increase in the risk of stroke at one-year follow-up (8.8\% in the TAVI group versus $12.6 \%$ in the SAVR group, $P=0.10)$.

\section{Registry data}

In 2011, the SOURCE (Edwards SAPIEN Aortic Bioprosthesis European Outcome) registry reported one-year outcomes for 1,038 patients enrolled in 32 centers across Europe. ${ }^{21}$ Of these patients, 575 had TAVI via a transapical approach and 463 via a transfemoral approach, with a Kaplan-Meier oneyear survival of $76.1 \%$ overall $(72.1 \%$ for transapical patients and $81.1 \%$ for transfemoral patients). The UK-TAVI registry data summarized the experience with 870 patients who had TAVI between 2007 and 2009 (Medtronic CoreValve, $n=452$ and Edwards SAPIEN, $n=410) .{ }^{22}$ Sixty-nine percent of these implants were transfemoral, with overall survival of $93 \%$, $78.6 \%$, and $73.7 \%$ at 30 -day, one-year, and 2-year follow-up, respectively. Gilard et al reported a mortality rate of $9.7 \%$ and $24 \%$ at 30 days and one year, respectively, in FRANCE-2 (the French registry), which enrolled 3,195 patients at 34 centers in France between January 2010 and October 2011 (33\% Medtronic CoreValve and 67\% Edwards SAPIEN). ${ }^{23} \mathrm{Di}$ Mario et al reported the 2011-2012 European sentinel pilot registry data for 4,571 TAVI patients from 137 centers, with an inhospital mortality of $7.4 \%$. and this was similar in both SAPIEN-XT'TM and CoreValve patients. ${ }^{24}$

\section{Long-term data}

Owing to the earlier application of TAVI in Canada, the Canadian registry has long-term follow-up data. Rodés-Cabau et al published the Canadian multicenter experience of 339 high-risk patients who underwent TAVI with a balloonexpandable valve (Cribier-Edwards [ $n=57]$, Edwards SAPIEN [ $\mathrm{n}=275]$, or SAPIEN XT [n=7]) between 2005 and $2009 .{ }^{25}$ The all-cause mortality was $56 \%$ (188 patients) after a mean follow-up of $42 \pm 15$ months $(10.4 \%$ died within 30 days and $44.8 \%$ died during follow-up). Toggweiler et al recently reported their single-center, 5-year outcomes for 88 patients who underwent TAVI. ${ }^{26}$ Median survival time after TAVI was 3.4 years, with one-year to 5-year survival rates of $83 \%, 74 \%, 53 \%, 42 \%$, and $35 \%$, respectively. Overall, the aortic valve area decreased on average by $0.06 \mathrm{~cm}^{2}$ per year (standard error $0.01 ; P<0.01$ for trend) and the mean gradients increased by an average of $0.27 \mathrm{mmHg}$ per year (standard error $0.15 ; P=0.06$ for trend) during 5 years of follow-up. There were no differences in gradients or aortic valve areas between the Cribier-Edwards and Edwards SAPIEN valves. The results of the ADVANCE core valve registry data, representing the real world experience of 1,015 patients from 44 international centers between March 2010 and July 2011, are very promising (albeit not as yet published). ${ }^{27}$ These results show a very high procedural success rate $(97.5 \%)$, with all-cause and cardiovascular mortality of $4.5 \%$ and $3.4 \%$ at 30 -day follow-up and $17.9 \%$ and $11.7 \%$ at one-year follow-up, respectively. The major published data are summarized in Table 1.

\section{Ongoing trials}

As a follow-up trial to the landmark PARTNER I trial, the PARTNER II trial is currently ongoing (ClinicalTrials. gov identifier NCT01314313). It consists of two parallel, randomized controlled trials. In an attempt to expand the indication of TAVI to lower-risk patients, the trial is designed to compare SAVR with the second-generation valve (SAPIEN XT) and delivery system (NovoFlex for transfemoral TAVI and Ascendra 2 for transapical TAVI) in intermediate-risk patients in the cohort A population. In the cohort B (inoperable) population, the PARTNER II trial is designed to study and compare the safety and effectiveness of the second-generation valve (SAPIEN XT) and delivery system (NovoFlex) with that of the first-generation valve (SAPIEN) and delivery system (RetroFlex3). It is 


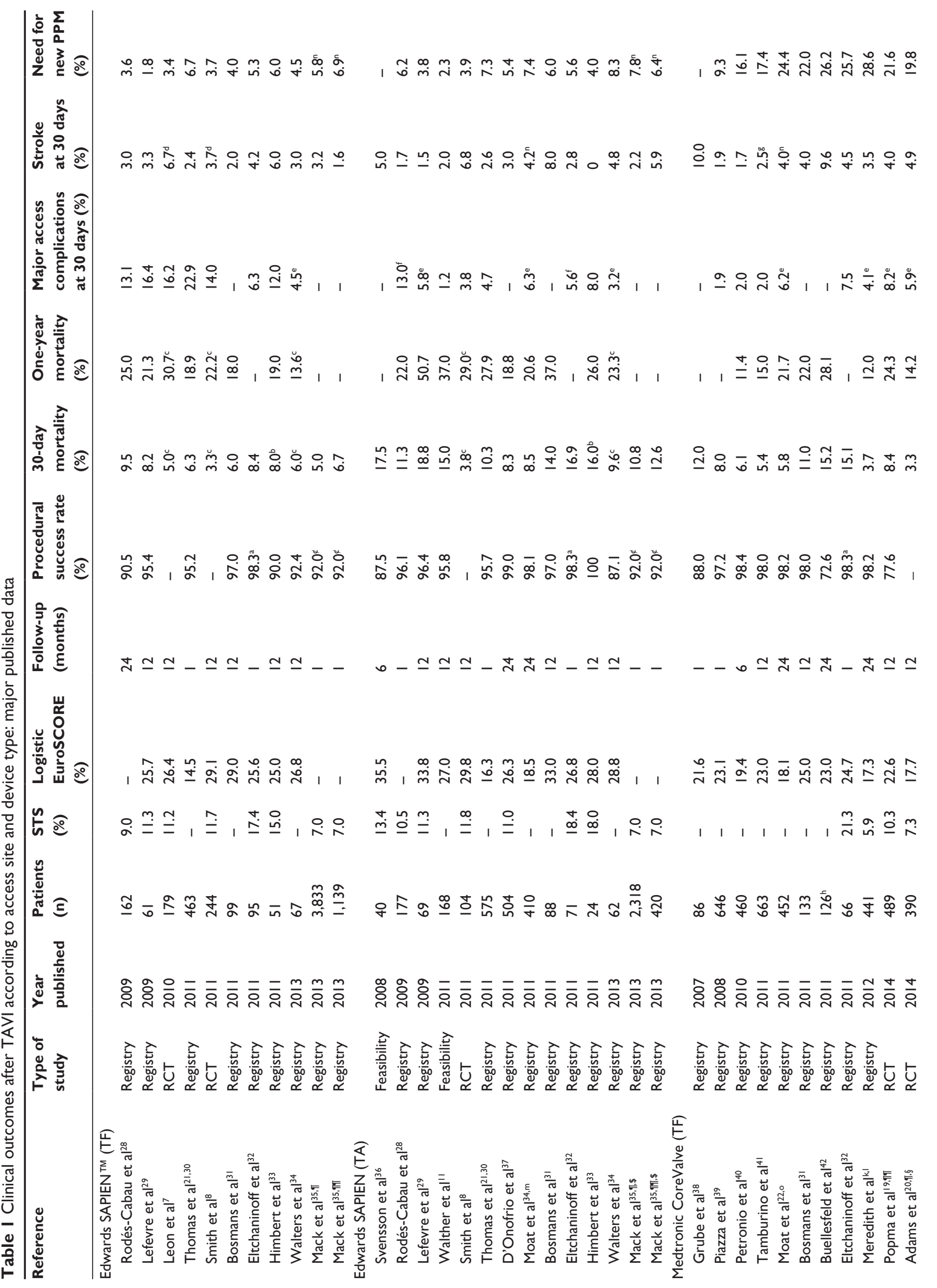




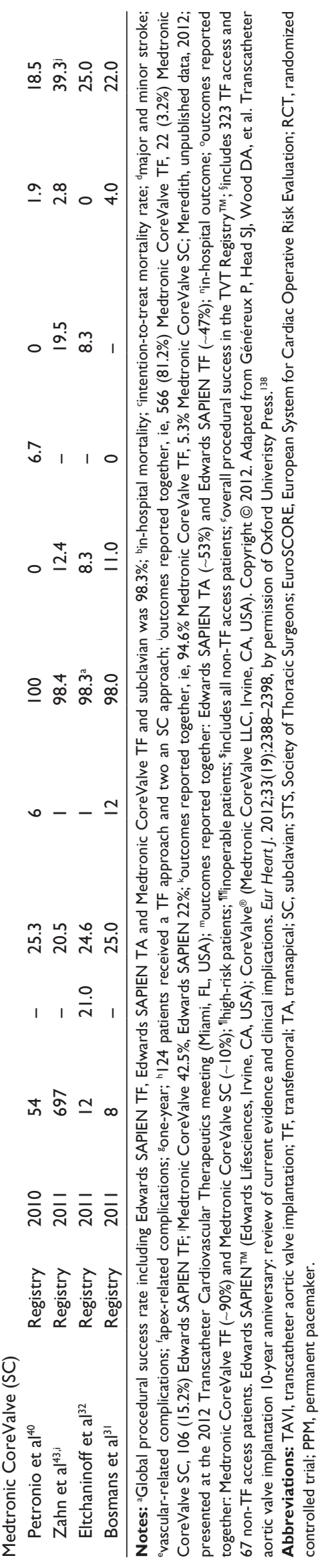

expected that the next-generation Edwards valve, which can be implanted using a lower profile transfemoral system (18/19 French with NovoFlex versus 22/24 French with RetroFlex 3), will further reduce vascular and access complications with TAVI, and results are expected in March 2015. Similarly, the SURTAVI trial (ClinicalTrials. gov identifier NCT01586910) is under way to evaluate the safety and efficacy of the Medtronic CoreValve system in the treatment of symptomatic severe aortic stenosis in subjects who are at intermediate risk (predicted Society of Thoracic Surgeons [STS] mortality risk score $\geq 4 \%$ and $\leq 10 \%$ ) for aortic valve surgery compared with SAVR. This international, prospective, randomized controlled study aims to recruit 2,500 patients in approximately 75 centers across the USA, Canada, Europe, and Australasia, and the results are expected in 2016.

\section{Who should we treat?}

Currently, TAVI is indicated in patients with symptomatic severe aortic stenosis who are deemed either inoperable or at high-risk for conventional SAVR. Severe aortic stenosis is defined as an aortic valve area $\leq 1.0 \mathrm{~cm}^{2}$ or $\leq 0.6 \mathrm{~cm}^{2}$ per $\mathrm{m}^{2}$. Patients are considered to be symptomatic if they have symptoms of exertional breathlessness (New York Heart Association class II-IV), angina, or syncope that are attributable to aortic stenosis. In the PARTNER I trial, highrisk patients (cohort A) were defined as those with a STS ${ }^{44}$ risk score of $\geq 10 \%$ or predicted risk of operative mortality $\geq 15 \%$ at 30 days and inoperable patients (cohort B) were defined as those with a predicted risk of operative mortality or serious, irreversible morbidity $\geq 50 \%$ at 30 days. Currently, no scoring system or predicted mortality by surgeons translates to events in the real world, indicating a need for a better mortality and morbidity scoring system for these valve patients. In PARTNER, the 30-day mortality in the surgical arm in cohort A was $6 \%-7 \%$. TAVI as a therapeutic option for symptomatic severe aortic stenosis is included in the recently published 2012 guidelines for management of valvular heart disease published by the Joint Task Force on the Management of Valvular Heart Disease of the European Society of Cardiology and the European Association for CardioThoracic Surgery, ${ }^{45}$ and also in the 2012 US Expert Consensus Document on Transcatheter Aortic Valve Replacement, ${ }^{46}$ and the indications and contraindications are summarized in Tables 2 and 3. The definition of high-risk versus inoperable state is arbitrary, and this should be considered a continuum. As far as patients with low or intermediate risk are concerned, there is no evidence to date regarding TAVI versus SAVR. Valve durability will 
Table 2 Indications for TAVI in severe aortic stenosis

\begin{tabular}{|c|c|c|}
\hline Recommendations & Class $^{a}$ & Level $^{\mathrm{b}}$ \\
\hline $\begin{array}{l}\text { TAVI should only be undertaken with a } \\
\text { multidisciplinary "heart team" including } \\
\text { cardiologists and cardiac surgeons and other } \\
\text { specialists if necessary. }\end{array}$ & I & C \\
\hline $\begin{array}{l}\text { TAVI should only be performed in hospitals } \\
\text { with cardiac surgery on site. }\end{array}$ & I & C \\
\hline $\begin{array}{l}\text { TAVI is indicated in patients with severe } \\
\text { symptomatic AS who are not suitable for AVR } \\
\text { as assessed by a "heart team" and who are likely } \\
\text { to gain improvement in their quality of life and } \\
\text { to have a life expectancy of more than one year } \\
\text { after consideration of their comorbidities. }\end{array}$ & I & B \\
\hline $\begin{array}{l}\text { TAVI should be considered in high-risk patients } \\
\text { with severe symptomatic AS who may still be } \\
\text { suitable for surgery, but in whom TAVI is } \\
\text { favored by a "heart team" based on the } \\
\text { individual risk profile and anatomic suitability. }\end{array}$ & Ila & B \\
\hline
\end{tabular}

Notes: a Class of recommendation; blevel of evidence.

Copyright (C) 2012. Reprinted from Vahanian A, Alfieri O, Andreotti F, et al. Guidelines on the management of valvular heart disease (version 2012): the Joint Task Force on the Management of Valvular Heart Disease of the European Society of Cardiology (ESC) and the European Association for Cardio-Thoracic Surgery (EACTS). Eur J Cardiothorac Surg. 2012;42:SI-S44, by permission of Oxford University Press. ${ }^{45}$

Abbreviations: AS, aortic stenosis; AVR, aortic valve replacement; TAVI, transcatheter aortic valve implantation.

be an important factor when extending TAVI to this group, given that patients are likely to live longer following corrective surgery. The ongoing PARTNER II and SURTAVI trials might shed light on the question of efficacy in this risk group and durability in vivo. With the current pricing of the device, the cost-effectiveness of this program lies in treating high-risk surgical patients who are likely to live at least more than a year as determined by the heart team. However, the willingness to pay to save a life will vary based on the gross domestic product of each country.

\section{Complications of TAVI}

Despite being less invasive than the SAVR, TAVI is associated with serious complications including stroke, vascular complications, paravalvular aortic regurgitation (AR), and conduction abnormalities. These major complications remain the "Achilles heel" of TAVI in terms of becoming a widely accepted alternative to SAVR, especially with the move towards treating intermediate-risk patients. The Valve Academic Research Consortium (VARC) has attempted to standardize the definitions of complications to encourage uniform reporting. ${ }^{47,48}$

\section{Cerebrovascular events}

Stroke is the most dreaded complication of interventional cardiology procedures, and is associated with not only increased mortality but also increased morbidity and
Table 3 Contraindications to transcatheter aortic valve implantation

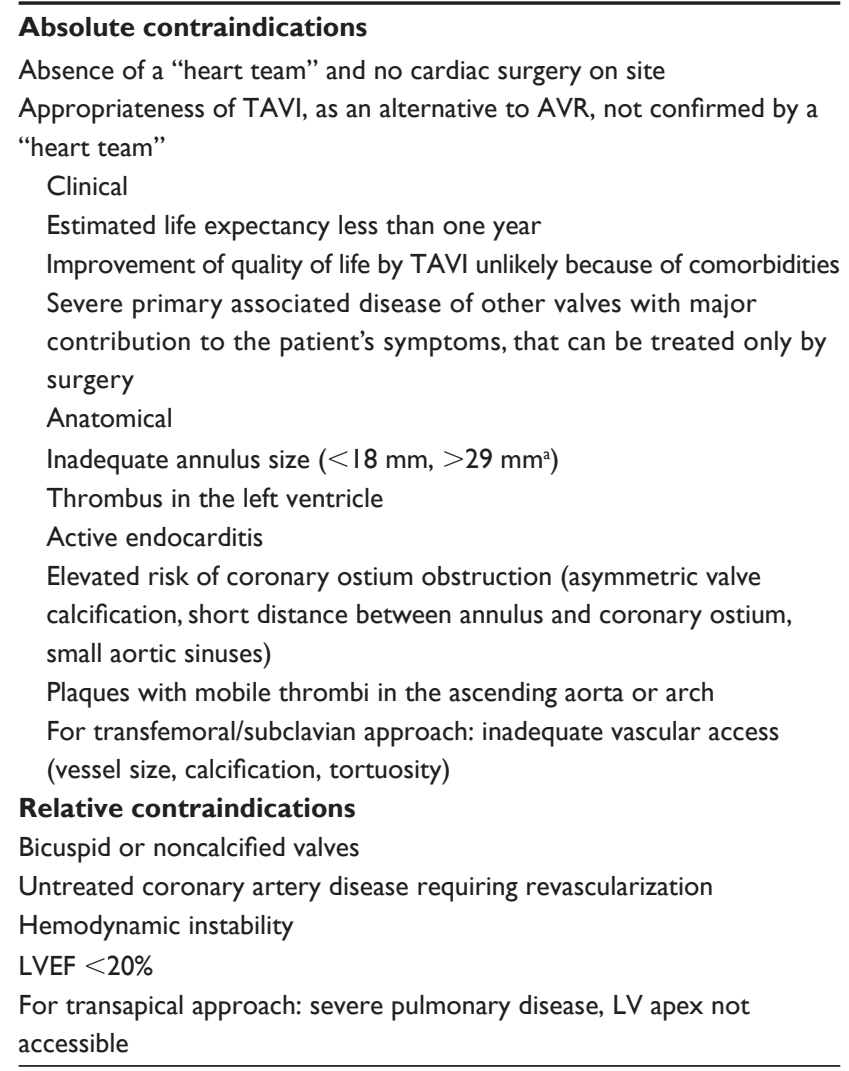

Notes: ${ }^{2}$ Contraindication when using the current devices.

Copyright $\odot$ 2012. Reprinted from Vahanian A, Alfieri O, Andreotti F, et al. Guidelines on the management of valvular heart disease (version 20I2): the Joint Task Force on the Management of Valvular Heart Disease of the European Society of Cardiology (ESC) and the European Association for Cardio-Thoracic Surgery (EACTS). Eur J Cardiothorac Surg. 2012;42:SI-S44, by permission of Oxford University Press. ${ }^{45}$

Abbreviations: AVR, aortic valve replacement; LV, left ventricle; LVEF, left ventricular ejection fraction; TAVI, transcatheter aortic valve implantation.

long-term disability. Not surprisingly, elderly patients who are currently referred for TAVI are often as concerned about stroke as about dying during the procedure. The overall rate of stroke after conventional isolated aortic valve replacement is approximately $1.5 \%$ according to the STS database, but may be increased to $2 \%-4 \%$ in older or high-risk populations. ${ }^{49}$ In the PARTNER I trial, major strokes were observed more frequently in the TAVI group, both in cohort B (compared with standard therapy group) at 30 days (5.0\% versus $1.1 \%$, $P=0.06)$ and at one year $(7.8 \% \text { versus } 3.9 \%, P=0.18)^{7}$ and in cohort A (compared with the surgical group) at 30 days (3.8\% versus $2.1 \%, P=0.20)$ and at one year $(5.1 \%$ versus $2.4 \%, P=0.07){ }^{8}$ This was somewhat attributed to the early iterations of large delivery systems of the Edwards valve. Using the smaller delivery system of the CoreValve, the US Extreme Risk Iliofemoral Study demonstrated a stroke rate of $2.4 \%$ and $4.1 \%$ at 30 days and one year, respectively. ${ }^{19}$ Depending on the definition used, the reported incidence of 
stroke is quite variable in the published data (Table 1), but in a recent meta-analysis of 10,037 patients by Eggebrecht et al, the average cerebrovascular event rates were $3.3 \% \pm 1.8 \%$ at 30 days and 5.2\% $\pm 3.4 \%$ at one-year follow-up. ${ }^{50}$ It was also noted that the 30-day mortality was 3.5-fold higher in patients who had stroke after TAVI compared with those without stroke. Diffusion-weighted magnetic imaging studies have revealed that clinically silent cerebral embolism occurs in up to $70 \%$ patients after TAVI ${ }^{51-53}$ Even though there was no measurable deterioration of neurocognitive function during 3 months of follow-up, ${ }^{52}$ the long-term effects of these silent strokes are unknown. The common underlying mechanism is embolization. Intraprocedural transcranial Doppler suggested that neurological events may occur at different time points during the procedure and relate to manipulation of the catheter through the calcified aortic arch, positioning of the device, performance of balloon aortic valvuloplasty, and inadequate blood flow to the brain during rapid pacing. ${ }^{54,55}$ These periprocedural events can be viewed as the consequences of embolization of calcified material or atheromatous debris from the aorta.

Even though the stroke risk is highest in the first week post TAVI, detailed analysis of the PARTNER trial revealed that this risk continues beyond the early phase. ${ }^{56}$ Predictors of early neurological events post TAVI included a prior neurological event, more severe atherosclerotic burden, and smaller valve area, while more advanced functional disability, previous stroke, and transapical access are predictors of late events. Remaining native calcified aortic valve and thrombogenicity of the stent of the prosthesis are also significant risk factors for late strokes. Recently, atrial fibrillation was also reported as a potential risk factor for stroke after TAVI, with more than one third of patients noted to have transient atrial fibrillation during their hospital stay. ${ }^{57}$ Although atrial fibrillation was not associated with increased mortality, it has been shown to increase the risk of stroke by four-fold..$^{57,58}$

\section{Paravalvular AR after TAVI}

During SAVR, the heavily calcified valve is initially excised and a new prosthesis is sutured to the annulus, resulting in a better seal with a low incidence of significant $(\geq 2+)$ paravalvular AR (4.2\%). ${ }^{59}$ Paravalvular AR is a much more frequent complication after TAVI, and depending on the method of assessment, the initial reported rates for trivial to mild AR were $40 \%-67 \%$ and for moderate to severe AR were $7 \%-20 \%{ }^{60-62}$ Device undersizing, aortic valve calcium, and suboptimal device implantation were the major predictors of AR after TAVI. ${ }^{63-68}$ In the PARTNER trial, moderate or severe paravalvular AR was more common after TAVI than after surgical replacement $(7.0 \%$ versus $1.9 \%$ at one year and $6.9 \%$ versus $0.9 \%$ at 2 years; $P<0.001) .{ }^{15}$ Quantification of paravalvular AR has been challenging, and has been revised between the VARC 1 and 2 publications, ${ }^{47,48}$ and does not conform to the American Society of Echocardiography. ${ }^{69}$ All agree that paravalvular $\mathrm{AR} \geq 2+$ is associated with increased mortality. During the 2-year follow-up, paravalvular AR remained unchanged, improved, and worsened in 46\%, 32\%, and $22 \%$ respectively. In a meta-analysis of 12,926 patients (CoreValve $41 \%$ ), the overall incidence of moderate to severe AR was $13.9 \%$ and trivial to mild AR was $46 \%$, as per VARC guidelines. ${ }^{70}$ While there is no direct comparison between the two valve types, this meta-analysis revealed that the CoreValve was associated with a higher rate of AR compared with the Edwards valve (16.0\% versus $9.1 \%$, $P=0.005)$. This may be related to the fact that the CoreValve continues to expand over 24-48 hours to improve its sealing, hence, AR may look worse with this device if assessed immediately after TAVI. This theory was supported by the recent US CoreValve trial results, ${ }^{19}$ in which the frequency of moderate or severe paravalvular AR was $10.7 \%$ at discharge and improved to $4.2 \%$ at 12 months, suggesting that there is ongoing remodeling at the annular-bioprosthesis interface with the self-expanding nitinol frame. Paravalvular AR due to malposition of the CoreValve is more evident because the valve is more forgiving and will function normally without embolizing under less precise deployment. Traditionally, a slightly higher AR has been considered acceptable, if tolerated by the patient. The radial strength of the self-expanding nitinol frame (CoreValve) compared with the balloonexpandable cobalt chromium (Edwards valve) stent may be suboptimal in terms of obtaining adequate sealing.

\section{Conduction abnormalities}

Atrioventricular block with subsequent need for permanent pacemaker implantation is one of the major complications of aortic valve intervention. The left bundle branch exits approximately $2-3 \mathrm{~mm}$ below the base of the interleaflet triangle separating the noncoronary and right coronary leaflets of the aortic valve and fans along the ventricular septum to supply the left ventricle. ${ }^{71}$ Because of this close anatomical relationship between the aortic valve and the branching atrioventricular bundle, aortic valve replacement may result in injury to subendocardial conduction tissue, causing the increased incidence of left bundle branch block. Rates of new permanent pacemaker implantation after TAVI in the literature vary greatly (Table 1) and this may be due to variations in practice regarding the threshold for permanent 
pacemaker implantation and variable reporting among physicians. A recent meta-analysis of 8,536 patients who had aortic valve replacement including SAVR as well as TAVI using both the Medtronic CoreValve and Edwards SAPIEN valve reported that the rate of new permanent pacemaker implantation was $5.9 \%$ and $12.10 \%$ after SAVR and TAVI (overall), respectively. ${ }^{72}$ There was a higher incidence of new permanent pacemaker implantation in CoreValve patients (24.50\%) compared with Edwards SAPIEN valve patients (5.8\% via transfemoral and $6.9 \%$ via transapical). A higher radial force and increased depth of implantation into the left ventricular outflow tract are factors potentially associated with the increased permanent pacemaker implantation after TAVI using the CoreValve. ${ }^{73,74}$ Nazif et al recently reported that persistent, new-onset left bundle branch block occurred in $10.5 \%$ of patients without baseline intraventricular conduction abnormalities who underwent TAVI in the PARTNER trials. $^{75}$ New left bundle branch block was not associated with death, repeat hospitalization, stroke, or myocardial infarction at one year, but was associated with a higher rate of permanent pacemaker implantation at one year (4.7 versus $1.5 \%, P=0.01$ ) and failure of left ventricular ejection fraction to improve. A recent study showed that only one third of the patients implanted with a permanent pacemaker post TAVI were pacemaker-dependent at one-year follow up, ${ }^{76}$ suggesting that further studies are needed to determine the predictors of long-term pacing dependency.

\section{Vascular complications}

Major vascular complications and major bleeding are important barriers to improvement of patient outcomes after TAVI. The incidence of major vascular complications varies between $3.8 \%$ and $23 \%$ using the Edwards SAPIEN valve and between $2.0 \%$ and $14 \%$ using the CoreValve system (Table 1). Standardized definitions have been formulated for major and minor vascular complications by the VARC 2 consensus document to facilitate common clinical endpoints to increase consistency and comparability in TAVI clinical trials. ${ }^{48} \mathrm{~A}$ recent analysis of 419 transfemoral TAVI patients from the two PARTNER trials revealed an incidence of major and minor vascular complications at 30 -day follow-up of $15.3 \%$ and $11.9 \%$, respectively. ${ }^{77}$ Vascular dissection, perforation, and access site hematoma were the most common vascular complications. Major vascular complications were associated with significantly higher 30-day rates of major bleeding, transfusions, and renal failure requiring dialysis, and with a significantly higher rate of mortality at 30 days $(14.1 \%$ versus $3.1 \%, P<0.0001)$ and one year (39.4\% versus $22.8 \%, P=0.001)$. Sheath size $>19$
French, female sex, a sheath-to-femoral artery ratio $>1.05$, and femoral artery calcification are independent predictors for major vascular complications while learning effect is associated with reduced complications. ${ }^{78,79}$

\section{Repositioning of the valve and embolization}

An ideal transcatheter aortic prosthesis would restrain the native leaflets and relieve stenosis without having unnecessary contact with the surrounding structures. A valve extending excessively into the ventricle or the aorta might be associated with adverse events such as aortic insufficiency, conduction abnormalities, mitral valve dysfunction, coronary obstruction, or valve embolization. Repositioning of a malpositioned valve is advantageous to reduce complications; however, the firstgeneration valves are not repositionable. The self-expanding CoreValve can be moved towards the aorta to some degree, whereas the balloon-expanding valves (Edwards SAPIEN and SAPIEN-XT) do not have this flexibility.

Valve embolization is a rare but serious complication after TAVI, with a reported incidence of $0.3 \%$ in the SOURCE registry data ${ }^{21}$ and $1.0 \%$ in the PARTNER I trials. ${ }^{80}$ Valve embolization is often related to technical factors, such as timing of balloon inflation and suboptimal rapid pacing, undersizing and inaccurate valve placement, anatomical factors such as a pre-existing mitral bioprosthesis with a protruding stent frame, a large septal knuckle and native leaflet rupture, or overhanging leaflets. ${ }^{80}$ Although valve embolization is mostly immediate, late embolization up to several hours has been reported. Patients with valve embolization were much more likely to require hemodynamic support and had higher rates of death $(26.9 \%$ versus $5.8 \%, P<0.0001$; $50.5 \%$ versus $21.0 \%, P<0.0001)$ and neurological events (13.2\% versus $3.7 \%, P=0.02 ; 13.2 \%$ versus $6.1 \%, P=0.10)$ at 30 days and one year, respectively. Embolization to the aorta is generally well tolerated, and typically the valve can be snared or repositioned with a partially inflated valvuloplasty balloon into a more stable position in the aorta with implantation of another valve. Embolization to the left ventricle is poorly tolerated and would require surgical removal. ${ }^{81}$

\section{Technical advancements/ considerations to reduce complications \\ Cerebrovascular events}

Given that the majority of strokes are due to thromboembolism and occur in the first few days after the TAVI procedure, 
three mechanical cerebral embolic protection devices are being tested, ie, the Claret Pro system (Claret Medical, Santa Rosa, CA, USA), the TriGuard ${ }^{\circledR}$ (Keystone Heart Ltd, Herzliya, Israel), and the Embrella embolic deflector ${ }^{\mathbb{R}}$ (Edwards Lifesciences, Table 4). Although the initial results demonstrated safety with a high procedural success rate, there is a lack of convincing evidence with regard to reduction of new cerebral embolic lesions detected by diffusion weighted magnetic resonance imaging, and further studies are needed to determine the clinical efficacy of these devices. ${ }^{82-84}$

Grube et al evaluated the feasibility of TAVI without balloon predilation in 60 patients, and the results are encouraging, with low stroke rates $(5 \%){ }^{85} \mathrm{~A}$ larger randomized trial is currently recruiting 110 patients to test this hypothesis (SIMPLIFy TAVI, ClinicalTrials.gov identifier NCT01539746).

Current recommendations regarding pharmacotherapy during and after TAVI are made on an empiric basis and there is no randomized data. A pathological study revealed that it takes about 3 months for the valve to be completely endothelialized. ${ }^{86}$ Current recommendations suggest dual antiplatelet therapy with aspirin (long-term) and clopidogrel (1-6 months), ${ }^{45,46}$ but the optimal dosage and duration of treatment is unknown. A randomized trial is underway to address this (ARTE trial, ClinicalTrials.gov identifier NCT01559298). Current anticoagulation therapy during TAVI includes unfractionated heparin (activated clotting time approximately $250-350$ seconds) followed by reversal with protamine at the end of procedure in some centers. Bivalirudin, a direct thrombin inhibitor, has been tested as an alternative to heparin, and following the initial encouraging results during balloon aortic valvuloplasty ${ }^{87}$ and TAVI, ${ }^{88}$ a larger international randomized study is currently underway (BRAVO-3 trial, [Effect of Bivalirudin on Aortic Valve Intervention Outcomes], ClinicalTrials.gov identifier NCT01651780). Similarly, with more evidence

Table 4 Design, advantages, and disadvantages of the currently available cerebral protection devices used during transcatheter aortic valve implantation

\begin{tabular}{ll}
\hline $\begin{array}{l}\text { Cerebral } \\
\text { protection devices }\end{array}$ & Design \\
\hline & $\begin{array}{l}\text { Has two filters, a proximal that consists } \\
\text { of a nitinol frame, and a polyurethane } \\
\text { filter with } 140 \mu \mathrm{m} \text { diameter pores } \\
\text { which is attached to a } 100 \mathrm{~cm} \text { catheter } \\
\text { and a non-proprietary distal filter. } \\
\text { The proximal filter is placed to the } \\
\text { right brachiocephalic artery whereas } \\
\text { the distal filter is placed to the left } \\
\text { common carotid artery }\end{array}$ \\
\end{tabular}
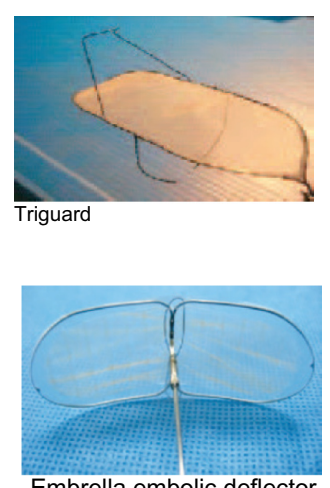

Consists of a nitinol mesh that is fixed onto a nitinol frame and is used to deflect the debris, 2 stabilisers that provide fixation of the device on the aortic arch, and a tail end that connects the device with the delivery system

Incorporates a heparin-coated polyurethane membrane that is mounted on a nitinol frame which is attached to a $110 \mathrm{~cm}$ catheter. The device has three radiopaque markers which facilitate the correct positioning of the device

\section{Advantages Limitations}

Requires a small sheath (6 Fr). Is able to capture the debris delivered during the procedure

It can be implanted through both the left and right femoral arteries. Permits full coverage of the supra-aortic trunk. Can be left in the aortic arch for days

Requires a small sheath $(6 \mathrm{Fr})$
Can be implanted only through the right radial/brachial artery and not through an alternative access. The device has to be removed post procedure. Does not protect the left vertebral artery and in a small feasibility study it was possible to deploy the distal filter in only $73 \%$ of the patients studied. Small-scale studies have shown that the device can capture debris derived from the aorta and the aortic valve during TAVI; however, there is no clinical evidence in the context of a randomised control trial to support the use of the device during TAVI

It is a deflector device that redirects debris away from the brain towards the descending aorta. Requires a relatively large sheath $(9 \mathrm{Fr})$. Although it has been tested in a small feasibility study there are no robust randomised clinical data to support its use in everyday practice Cannot be deployed through an alternative access point. Does not protect always the left vertebral artery. It is a deflector device that redirects emboli away from the brain towards the peripheral arteries. There is a lack of evidence to support the value of the device in a clinical setting

Note: Copyright ( 2 2013. Reprinted from Bourantas CV, Van Mieghem NM, Soliman O, Campos CA, lqbal J, Serruys PW. Transcatheter aortic valve update 2013. Eurolntervention. 2013;9 Suppl:S84-S90, with permission from Europa Digital and Publishing. ${ }^{20}$

Abbreviation: TAVI, transcatheter aortic valve implantation. 
emerging about periprocedural atrial fibrillation as a cause of stroke, further studies are needed to explore the potential efficacy of prophylactic use of antiarrhythmic drugs to prevent atrial fibrillation and antithrombotic agents like warfarin to prevent strokes.

\section{Paravalvular AR after TAVI}

Undersizing of the prosthesis relative to the patient's aortic annulus is a main reason for paravalvular AR after TAVI. As the aortic valve annulus is not circular in shape, assessment with two-dimensional echocardiography can underestimate the valve size. Several studies have shown that the annulus measurement by multidetector computed tomography is a better predictor of annulus size and is associated with reduced rates of AR after TAVI. ${ }^{89-91}$ Three-dimensional transesophageal echocardiography measurements have also been shown to be superior to two-dimensional transesophageal echocardiography and correlate closely with those from multidetector computed tomography ${ }^{92,93}$ but the resolution of this modality is yet to improve. Detaint et al reported that occurrence of significant AR was closely associated with a lower cover index (cover index $=100 \times$ [prosthesis diameter - transesophageal echocardiography annulus diameter]/prosthesis diameter) and that there was no significant AR when the measured cover index was $>8 .{ }^{63}$

Paravalvular AR after TAVI is closely associated with the implantation depth, ${ }^{94}$ and if the valve is positioned too low or high, the skirt of the prosthetic valve (9-13 mm height) does not provide an adequate seal around the annulus, leading to significant AR. The ideal implant height to reduce the paravalvular AR and conduction abnormality will be around 2-6 mm below the virtual annulus. ${ }^{95}$ Valve position is currently based on fluoroscopy with or without intraprocedural transesophageal echocardiography guidance. The recent advances in imaging technology allow comprehensive real time visualization, which helps in optimal positioning of the prosthesis. The newer imaging systems use computer reconstruction techniques to predict the optimal angiographic views by processing either the aortogram acquired before device deployment (C-THV system, Paieon Inc., New York, NY, USA) or the computed tomography data (3-mensio valve, 3mensio Medical Imaging, Bilthoven, NL, and OSIRIX, Pixmeo SARL, Switzerland). The Philips heart navigator system (Philips, Eindhoven, the Netherlands) provides threedimensional reconstruction of the aorta and aortic valve by superimposing the computed tomography data onto the angiographic projections, while the DynaCT (Siemens AG, Erlangen, Germany) and Vitrea (Vital images [Toshiba],
Plymouth, MN, USA) use the rotational two-dimensional fluoroscopic images acquired in the catheterization laboratory to reconstruct a three dimensional aortic valve anatomy. Small studies have shown the utility of these technologies, with better positioning of the valve reducing paravalvular AR. ${ }^{96,97}$

During the procedure, careful hemodynamic monitoring helps to identify significant AR after TAVI. Loss of the dicrotic notch, low diastolic pressure, and high left ventricular end-diastolic pressure (LVEDP) may indicate significant AR. Sinning et al proposed an AR index (AR index = aortic diastolic pressure - LVEDP/aortic systolic pressure) and reported that a low AR index correlates closely with significant AR after TAVI; an AR index $<25$ was associated with significantly higher mortality $(46.0 \%$ versus $16.7 \%, P=0.001) .{ }^{98}$

Several interventional techniques have been suggested to treat significant AR intraprocedurally, including balloons, snares, and valve-in-valve. ${ }^{99}$ If the valve position is adequate, but associated with significant $\mathrm{AR}$, then postdilation with an oversized balloon may improve the sealing and reduce paravalvular AR. ${ }^{46}$ This has not led to any deleterious effect on valve hemodynamics as measured by echocardiography at one-year follow-up, but caution is needed because post dilation may be associated with an increased risk of cerebrovascular events. ${ }^{100}$ If the valve is implanted too low, the CoreValve can be snared towards the aorta. Although successful cases have been reported, ${ }^{101,102}$ the valve may move back to the original position once the tension is released or has the potential risk of valve embolization, damage to the heavily calcified aorta or cerebral embolic events. Hence, valve-in-valve has been suggested as a preferred technique for both the Edwards and the CoreValve in this scenario. ${ }^{103}$ Ussia et al reported their valve-in-valve experience in 24 of 663 patients (3.6\%) undergoing TAVI using CoreValve in the Italian registry. ${ }^{104}$ At 12 -month follow-up, the mean gradient was $10.5 \pm 5.2 \mathrm{mmHg}$, which was not different from that in patients undergoing a conventional CoreValve procedure. At 12 months, the major adverse cerebrovascular and cardiac event rates in the standard procedure and valve-in-valve groups were $4.5 \%$ and $14.1 \%$, respectively $(P=0.158)$, and the mortality rates were $4.5 \%$ versus $13.7 \%,(P=0.230)$. Toggweiler et al recently reported their valve-in-valve experience in 21 of 760 patients $(2.8 \%)$ undergoing TAVI using the balloon-expandable device (Edwards valve). ${ }^{105}$ The mean transvalvular gradient was higher in the valve-in-valve group compared with the conventional TAVI group (15 \pm 4 $\mathrm{mmHg}$ versus $11 \pm 4 \mathrm{mmHg}$, respectively, $P=0.02$ ), but one- 
year mortality rates were similar (24\% versus $22 \%$ ). However, a recent analysis of the PARTNER trials suggests that at one year, patients with valve-in-valve had higher all-cause mortality (33.3\% versus $21.0 \%, P=0.02)$, cardiovascular mortality $(24.4 \%$ versus $9.1 \%, P=0.0005)$, and a trend to more rehospitalization $(25.5 \%$ versus $17.7 \%, P=0.12) .{ }^{80}$ There is also concern regarding increased risk of thrombosis, and the optimal duration of antiplatelet/anticoagulation therapy in these patients is unknown. Successful percutaneous closure of paravalvular leaks after TAVI using vascular plugs has also been described. ${ }^{106,107}$ A SAVR may be a final option for patients with acute severe AR following TAVI with hemodynamic compromise, if all other interventional options are exhausted. ${ }^{108}$ Several new valve designs are being developed to address this complication and are discussed below.

\section{Conduction abnormalities}

Predictors of complete atrioventricular block post TAVI include presence of right bundle branch block before TAVI, low implantation of the prosthesis, and prosthesis oversizing. ${ }^{109,110}$ Piazza et al reported that no patient in their study developed prosthesis-related left bundle branch block when the proximal end of the valve frame was positioned $<6.7 \mathrm{~mm}$ from the lower edge of the noncoronary cusp. ${ }^{73}$ More than $90 \%$ of all atrioventricular blocks requiring implantation of a permanent pacemaker occurred immediately or within 7 days after TAVI. ${ }^{110}$ Therefore, prompt recognition and appropriate management of atrioventricular block remain essential, and continuous electrocardiographic monitoring has been recommended for at least 72 hours post TAVI for all patients at increased risk of this complication. ${ }^{46}$ Novel valve prostheses are being developed to reduce various complications, including conduction abnormalities after TAVI (Table 5). Some of the features of the newer valves that may minimize damage to the cardiac conduction system include low frame height (Direct Flow Medical valve, Direct Flow Medical Inc., Santa Rosa, CA, USA; SAPIEN III and Centera valves from Edwards Lifesciences) and low placement of the leaflets within the prosthesis to minimize frame protrusion into the left ventricular outflow tract (Lotus valve, Boston Scientific, Natick, MA, USA; JenaValve system, JenaValve Technology GmbH, Munich, Germany; Portico $^{\mathrm{TM}}$ valve, St Jude Medical, St Paul, MN, USA; and Acurate TA TM valve, Symetis SA, Ecublens, Switzerland). Having the ability to reposition the valve (Table 5) may aid the surgeon to confidently implant the valve higher and reduce the need for a permanent pacemaker. As the practice of TAVI evolves, it remains to be seen how the next generation of
TAVI prostheses will affect the incidence, risk factors, and clinical outcomes of associated conduction disturbances.

\section{Vascular complications}

By reducing the sheath vessel ratio, we can reduce the vascular complications. ${ }^{79}$ The Edwards SAPIEN valve introducer sheath is constantly coming down, from 22 and 24 French, to 18-19 French, to the current 16, 18, and 20 French e-sheath for 23, 26, and $29 \mathrm{~mm}$ valves, respectively. The new SAPIEN 3 can be delivered via a 14 French e-sheath. It is important to note that the expandable sheath transiently increases by 5-6 French sizes during passage of the valve. The CoreValve started with a 25 French delivery sheath that came down to 22 French and currently uses 18 French for all valve sizes. The Evolut R ${ }^{\mathrm{TM}}$ (a new iteration of the CoreValve) will have a true 14 French inline sheath for delivery. Reducing from the 22-24 French to 18-19 French sheath has been shown to reduce major vascular complications by three-fold ( $11.1 \%$ versus $33.3 \%, P=0.004) .{ }^{111}$ In the recently presented preliminary results of the PARTNER II B trial (inoperable patients), the major vascular complication rate at 30 days were $9.6 \%$ with the SAPIEN XT valve (18/19 French) versus $15.5 \%$ with the SAPIEN valve (22/24 French). ${ }^{112}$ Lately, a balloon-expandable sheath, Solopath ${ }^{\circledR}$ (Terumo Corporation, Somerset, NJ, USA), has been used to deliver the Medtronic CoreValve. This has a distal tip with a 13 French diameter that can be expanded with the use of a balloon to the nominal diameter of 19 French after being advanced into the aorta, and the initial results in a small series of patients are encouraging. ${ }^{113}$

Frequent surgical cut-down and vascular repair were commonly performed with the larger sheaths during the early years ofTAVI, but with the availability of low-profile sheaths, several vascular closure devices have been tested to reduce vascular complications. Currently available closure devices include the ProStar XL (Abbott Vascular, Santa Clara, CA, USA) and the ProGlide (Abbott Vascular) for the transfemoral approach and the APICA ASC ${ }^{\text {TM }}$ (APICA Cardiovascular, Galway, Ireland) for the transapical approach, while others such as the ProMed (ProMed Inc., Santa Clara, CA, USA) and the InSeal (InSeal Medical, Caesarea, Israel) for transfemoral access and the Permaseal ${ }^{\mathrm{TM}}$ (Micro Intervention Devices, Bethlehem, PA, USA) for transapical access are being developed.

Given that the predictive factors for vascular complications include peripheral vascular disease, vascular calcification, and vessel tortuosity, multimodality screening of the vascular access is of paramount significance in 
Table 5 Features of the second-generation transcatheter aortic valves that may reduce the risk of complications

\begin{tabular}{|c|c|}
\hline Second-generation valves & Features of the second-generation valves \\
\hline \multirow{4}{*}{ Direct flow medical } & Repositionable \\
\hline & Retrievable after being fully deployed \\
\hline & Low frame height designed to minimise conduction disturbances \\
\hline & Bovine pericardial leaflets for increased durability \\
\hline \multirow{6}{*}{ Jena } & Repositionable \\
\hline & Anchoring system that facilitates optimal deployment \\
\hline & Tactile feedback during deployment \\
\hline & Low placement of the leaflets of the valve to minimise frame protrusion in the left ventricular outflow tract \\
\hline & Large stent design to reduce the risk of coronary ostium obstruction \\
\hline & Markers to facilitate device deployment \\
\hline \multirow{5}{*}{ Engager } & Repositionable \\
\hline & Anchoring system that facilitates optimal deployment \\
\hline & Tactile feedback during deployment \\
\hline & Markers to facilitate device deployment \\
\hline & Bovine pericardial leaflets and anticalcification technology for increased durability \\
\hline \multirow{6}{*}{ Portico } & Repositionable \\
\hline & Low placement of the leaflets of the valve to minimise frame protrusion in the left ventricular outflow \\
\hline & tract \\
\hline & Large stent design to reduce the risk of coronary ostium obstruction \\
\hline & Markers to facilitate device deployment \\
\hline & Bovine pericardial leaflets and anticalcification technology for increased durability \\
\hline \multirow{7}{*}{ Acurate } & Repositionable \\
\hline & Anchoring system to facilitate optimal positioning \\
\hline & Low placement of the leaflets of the valve to minimise frame protrusion in the left ventricular outflow tract \\
\hline & Tactile feedback during deployment \\
\hline & Markers to facilitate device deployment \\
\hline & Additional cuff to reduce the risk of paravalvular leak \\
\hline & Anticalcification technology for increased durability \\
\hline \multirow{7}{*}{ CoreValve evolut $\mathrm{R}$} & Repositionable \\
\hline & Retrievable after being fully deployed \\
\hline & Low delivery profile \\
\hline & Large stent design to reduce the risk of coronary ostium obstruction \\
\hline & Markers to facilitate device deployment \\
\hline & Extended skirt and modified cell geometry to reduce the risk of paravalvular leak \\
\hline & Anticalcification technology for increased durability \\
\hline \multirow{6}{*}{ Sapien III } & Incorporates a distal flex mechanism and fine positioning control for accurate placement \\
\hline & Low delivery profile \\
\hline & Low frame height designed to minimise conduction disturbances \\
\hline & Circular deployment at the annulus for optimal haemodynamics \\
\hline & Additional cuff to reduce the risk of paravalvular leak \\
\hline & Bovine pericardial leaflets and anticalcification technology for increased durability \\
\hline \multirow{8}{*}{ Lotus } & Repositionable \\
\hline & Retrievable after being fully deployed \\
\hline & Tactile feedback during deployment \\
\hline & Low placement of the leaflets of the valve to minimise frame protrusion in the left ventricular \\
\hline & outflow tract \\
\hline & Additional cuff to reduce the risk of paravalvular leak \\
\hline & Markers to facilitate device deployment \\
\hline & Bovine pericardial leaflets and anticalcification technology for increased durability \\
\hline \multirow{6}{*}{ Centera } & Repositionable \\
\hline & Low delivery profile \\
\hline & Motorised handle with touch deployment allows precise device placement \\
\hline & Contoured frame designed for optimal seating and sealing in the annulus \\
\hline & Low frame height designed to minimise conduction disturbances \\
\hline & Bovine pericardial leaflets and anticalcification technology for increased durability \\
\hline \multirow{3}{*}{ Heart leaflet tech } & Repositionable \\
\hline & Markers to facilitate device deployment \\
\hline & Additional cuff to reduce the risk of paravalvular leak \\
\hline
\end{tabular}

Note: Copyright ( ) 2013. Reprinted from Bourantas CV, Van Mieghem NM, Soliman O, Campos CA, lqbal J, Serruys PW. Transcatheter aortic valve update 2013. Eurolntervention. 2013;9 Suppl:S84-S90, with permission from Europa Digital and Publishing. ${ }^{20}$ 
reducing the complications. Toggweiler et al have reported their experience with a fully percutaneous procedure using expandable sheaths, multidetector computed tomographic angiography for additional screening of the iliofemoral arteries, fluoroscopy/ultrasound-guided puncture, and preclosure using either two ProGlide devices (sutures implanted at 10 and 2 o'clock) or one Prostar. ${ }^{114}$ They reported decreases in major vascular complications from $8 \%$ to $1 \%(P=0.06)$, minor vascular complications from $24 \%$ to $8 \%(P<0.01)$, major bleeds from $14 \%$ to $1 \%(P<0.01)$, and unplanned surgery from $28 \%$ to $2 \%(P<0.01)$. When the femoral vasculature is unfavorable for TAVI, several alternative routes have been explored in addition to the transapical route, ie, the transaxillary, transaortic, and transcarotid approaches. ${ }^{115}$ There are no head-to-head comparisons between the various access sites for TAVI, but in general the nontransfemoral approach is associated with higher mortality when compared with transfemoral TAVI. In the recently published TVT Registry ${ }^{\mathrm{TM}}$ data, 30-day mortality was higher for nontransfemoral TAVI than for transfemoral TAVI $(10.8 \%$ versus $5.0 \%$ in high-risk patients and $12.6 \%$ versus $6.7 \%$ in inoperable patients). ${ }^{35}$ In a recent meta-analysis of about 6,500 patients, Li et al reported lower 30-day mortality with transfemoral TAVI when compared with transapical TAVI (7.5\% versus $11.3 \%$, respectively; odds ratio $0.63,95 \%$ CI 0.52-0.76) and no difference in rates of postoperative stroke or heart block. ${ }^{116}$ In a propensity-matched analysis, Petronio et al reported similar mortality rates at 2 years for TAVI using the subclavian approach compared with transfemoral TAVI. ${ }^{117}$ It should be noted that the current patient risk scoring systems (STS score and Logistic EuroSCORE) do not take into consideration other clinical factors (eg, severe peripheral vascular disease, frailty, obesity) that might affect selection of the access site in these patients, and it will be difficult to draw any conclusions regarding superiority of one access site over another until randomized controlled trials are conducted.

In recent years, sutureless aortic valve replacement (SUAVR) using minimally invasive surgical techniques has been proposed in high-risk patients as an alternative to conventional SAVR. Potential advantages of SU-AVR relate to removal of the native aortic valve and shortened aortic cross clamp times; however, other surgical steps including sternotomy/ ministernotomy, cardiopulmonary bypass, and aortic cross clamping, are still needed. Recent small propensity-matched studies have shown noninferiority for SU-AVR compared with transapical TAVI, with significantly better valve gradients compared with SAVR. ${ }^{18}$ There was a nonsignificant protection against pacemaker usage and AR with SAVR. Accepting the limitations of propensity-matching, SAVR appeared to be the best for survival and AR, validating the finding of the STACCATO study ${ }^{18}$ and the transapical arm of the Cohort A, PARTNER study. ${ }^{8}$ Given the limited data, SU-AVR may be considered in selected high-risk surgical patients as an alternative to TAVI when a transarterial approach is not available and as an alternative to SAVR to reduce patient-prosthesis mismatch. Recognizing the effect of operator and heart team experience on the outcome of TAVI, recent multisociety guidelines set minimum operator and institutional requirements for these procedures. ${ }^{119}$ With careful patient and access selection using multimodality imaging tools and using advanced interventional techniques with newer-generation, low profile sheaths, vascular complications can be minimized.

\section{Second-generation transcatheter aortic valves}

Several newer-generation devices have been developed to reduce the risk of complications associated with the firstgeneration transcatheter aortic valves, and Bourantas et al have summarized the features of these valves in a recent review $^{120}$ (Table 5). Most of these valves are repositionable and some are retrievable, even after being fully deployed (Lotus valve and Direct Flow Medical valve). To reduce the risk of paravalvular leak, valves are provided with either a special adaptive seal (Lotus valve), ${ }^{121}$ an additional cuff (SAPIEN III valve, ${ }^{122}$ Acurate valve, ${ }^{123}$ and HLT valve [Heart Leaflet Technologies Inc., Maple Grove, MN, USA], or an extended skirt (CoreValve Evolut R). Special Thermofix technology or anticalcification measures are being used on most new-generation valves to increase prosthesis durability. However, among the huge variety of anticalcification measures applied to conventional bioprostheses during the last few years, none turned out to expand durability significantly, and we need to be cautiously optimistic regarding the results of these measures in real world practice. Schofer et al recently reported their experience using the Direct Flow Medical valve in 75 patients and the results were encouraging, with $1 \%$ mortality, $4 \%$ stroke, and $1.4 \%$ moderate AR at 30 days. ${ }^{124}$ Preliminary results of the REPRISE-II trial (ClinicalTrials.gov identifier NCT01627691) using the Lotus valve presented by Meredith et al at the 2013 Transcatheter Cardiovascular Therapeutics meeting revealed $100 \%$ success in repositioning $(\mathrm{n}=31)$ and retrieval $(\mathrm{n}=6)$, with a $1 \%$ incidence of moderate AR at 30 days (data not published). 
Larger clinical trials are needed to confirm these findings prior to rolling out these devices for routine use.

\section{Future indications}

\section{Native aortic valve regurgitation}

TAVI has been used to treat patients with native aortic valve regurgitation who are deemed surgically inoperable, with "off-label" use of the CoreValve prosthesis and JenaValve device. What makes aortic insufficiency different from aortic stenosis is the lack of calcium in the aortic leaflets and annulus with unrestrained expansion of the aortic annulus, making it challenging to anchor the transcatheter heart valve. With the CoreValve, secondary anchoring in the ascending aorta contributes to stabilization, while with the JenaValve, feelers assist with positioning and anchoring at the level of the native cusps. Roy et al reported their experience with the CoreValve in 43 patients, indicating limited success, with 30-day mortality and major stroke rates of $9.3 \%$ and $4.7 \%$, respectively. ${ }^{125}$ Twenty-one percent of patients had residual moderate or severe AR and $18.6 \%$ required implantation of a second valve. Seiffert et al reported their experience with the JenaValve in a small series of patients, with no major procedure-related or device-related adverse events at 3 months. ${ }^{126}$ The Jena Valve is the only system that currently has a CE mark for this indication. The Helio dock (Edwards Lifesciences) is the first dedicated transcatheter device for the treatment of pure AR, ${ }^{127}$ that is performed as a fully percutaneous transarterial procedure (bilateral femoral access). The dock consists of a self-expandable nitinol stent encased in polyethylene terephthalate fabric that is fixed inside the aortic root and is intended to assist in annular fixation of a standard balloon-expandable SAPIEN XT valve. A potential advantage of this system is that incorporation of the native cusps into the device not only contributes to fixation but also provides paravalvular sealing. Pasupati presented feasibility study results at the 2013 EuroPCR conference in Paris, France, using a transapical and transfemoral approach, with successful implantation of the device in four patients, all of whom were alive at one-year follow up (not published).

\section{Valve-in-valve for a failing bioprosthesis}

Bioprostheses have limited durability, and most are expected to degenerate and eventually fail within $10-20$ years. ${ }^{128}$ A redo surgical valve replacement, which is the standard of care for patients with a failing bioprosthesis, is sometimes associated with high morbidity and mortality, especially in elderly patients, because of associated comorbidities. ${ }^{129}$ The valve-in-valve procedure has been proposed as an alternative to high-risk surgical valve replacement for patients with a failing bioprosthesis due to stenosis or regurgitation (transvalvular not paravalvular). Dvir et al recently summarized the global valve-in-valve registry experience in 202 patients from 38 centers $(61 \%$ with the CoreValve and $39 \%$ with the Edwards valve). ${ }^{130}$ Procedural success was $93.1 \%$, with $84.1 \%$ in New York Heart Association functional class II or less at 30 days. Mortality was $8.4 \%$ and $14.2 \%$ at 30 days and one-year follow-up, respectively. However, there were concerns with regard to elevated $(>20 \mathrm{mmHg}$ ) residual transaortic gradients in some patients (28.4\%), a high rate of device malposition (15\%), and a high rate of coronary obstruction (3.5\%), especially in selected Sorin bioprostheses (Mitroflow ${ }^{\circledR}$ in stented valves and Freedom ${ }^{\circledR}$ in stentless valves). It has been suggested that the supra-annular leaflet position in the CoreValve may allow for a larger orifice than can be achieved with annular leaflets constrained within the bioprosthetic valve ring, resulting in a lower incidence of high-transvalvular gradients with the CoreValve than with the Edwards valve, especially when implanted in a small surgical bioprosthesis $(<20-22 \mathrm{~mm})$. Specific issues have been reported with regard to selection of patients and the technical aspects of this technically challenging procedure. ${ }^{131,132}$ It is of paramount importance to understand the failed bioprosthetic valve (model, size, structure, position, and mode of failure) and to exclude thrombosis, endocarditis, and paravalvular regurgitation. It is also important to assess risk factors for coronary obstruction, given that a higher incidence has been reported with a valve-in-valve procedure than with TAVI in a native valve. Encouraging results of valve-in-valve as well as valve-inring implants at the mitral valve position have also been reported in a small series of patients. ${ }^{133,134}$ Currently, both the CoreValve and the Edwards valve have the CE mark for this indication.

\section{Valve implantation for "nonclassic" indications}

Pushing the limits further, successful cases of percutaneous valve implants have been reported for "nonclassic" indications, including bicuspid aortic valve, a failing bioprosthesis at the tricuspid valve, and valve-in-ring implantation at the tricuspid position. ${ }^{135-137}$ The Edwards and Melody (Medtronic, Minneapolis, MN, USA) valves have also been implanted in right ventricular pulmonary conduits. Further, the Edwards valve has been implanted in both the superior 
vena cava and the inferior vena cava to treat severe tricuspid regurgitation. Although the small number of patients included in these studies does not allow us to make any conclusions, it is likely that the indications of TAVI will broaden in the future.

\section{Conclusion}

TAVI has emerged as a viable alternative for high-risk or inoperable patients with symptomatic severe aortic stenosis. The results from the randomized controlled trials and the real world data show that the overall efficacy and survival at short to mid-term follow-up after TAVI is comparable with or superior to that with SAVR in high-risk patients. Even though rates of paravalvular AR, strokes, and vascular complications with the first-generation devices are higher than acceptable, these are likely to decrease with improvements in TAVI technology and increasing experience with implantation techniques. However, further research is required to answer the questions regarding durability of the valve, whether to use local anesthetic or general anesthetic, and whether to expand this procedure to low-risk patients and nonclassic indications.

\section{Disclosure}

Dr Pasupati is a proctor/consultant for the Medtronic, Edwards, and St Jude medical device companies. The authors have no other conflicts of interest in this work.

\section{References}

1. Iung B, Baron G, Butchart EG, et al. A prospective survey of patients with valvular heart disease in Europe: the Euro Heart Survey on Valvular Heart Disease. Eur Heart J. 2003;24:1231-1243.

2. Nkomo VT, Gardin JM, Skelton TN, Gottdiener JS, Scott CG, EnriquezSarano M. Burden of valvular heart diseases: a population-based study. Lancet. 2006;368:1005-1011.

3. Ross J Jr, Braunwald E. Aortic stenosis. Circulation. 1968;38: 61-67.

4. Bach DS, Siao D, Girard SE, Duvernoy C, McCallister BD Jr, Gualano SK. Evaluation of patients with severe symptomatic aortic stenosis who do not undergo aortic valve replacement: the potential role of subjectively overestimated operative risk. Circ Cardiovasc Qual Outcomes. 2009;2:533-539.

5. Cribier A, Eltchaninoff H, Bash A, et al. Percutaneous transcatheter implantation of an aortic valve prosthesis for calcific aortic stenosis: first human case description. Circulation. 2002;106: 3006-3008.

6. Grube E, Laborde JC, Zickmann B, et al. First report on a human percutaneous transluminal implantation of a self-expanding valve prosthesis for interventional treatment of aortic valve stenosis. Catheter Cardiovasc Interv. 2005;66:465-469.

7. Leon MB, Smith CR, Mack M, et al. PARTNER trial: transcatheter aortic-valve implantation for aortic stenosis in patients who cannot undergo surgery. N Engl J Med. 2010;363:1597-1607.

8. Smith CR, Leon MB, Mack MJ, et al. Transcatheter versus surgical aortic-valve replacement in high-risk patients. $N$ Engl J Med. 2011;364:2187-2198.
9. Cribier A, Eltchaninoff $\mathrm{H}$, Tron $\mathrm{C}$, et al. Treatment of calcific aortic stenosis with the percutaneous heart valve: mid-term follow-up from the initial feasibility studies: the French experience. J Am Coll Cardiol. 2006;47:1214-1223.

10. Kodali SK, O’Neill WW, Moses JW, et al. Early and late (one year) outcomes following transcatheter aortic valve implantation in patients with severe aortic stenosis (from the United States REVIVAL trial). Am J Cardiol. 2011;107:1058-1064.

11. Walther T, Kasimir MT, Doss M, et al. One-year interim follow-up results of the TRAVERCE trial: the initial feasibility study for transapical aortic-valve implantation. Eur J Cardiothorac Surg. 2011;39: 532-537.

12. Grube E, Laborde JC, Gerckens U, et al. Percutaneous implantation of the CoreValve self-expanding valve prosthesis in high-risk patients with aortic valve disease: the Siegburg first-in-man study. Circulation. 2006;114:1616-1624.

13. Webb JG, Chandavimol M, Thompson CR, et al. Percutaneous aortic valve implantation retrograde from the femoral artery. Circulation. 2006;113:842-850.

14. Makkar RR, Fontana GP, Jilaihawi H, et al. Transcatheter aortic-valve replacement for inoperable severe aortic stenosis. $N \mathrm{Engl} \mathrm{J} \mathrm{Med.}$ 2012;366:1696-1704.

15. Kodali SK, Williams MR, Smith CR. Two-year outcomes after transcatheter or surgical aortic-valve replacement. $N$ Engl J Med. 2012;366:1686-1695.

16. Hahn RT, Pibarot P, Stewart WJ, et al. Comparison of transcatheter and surgical aortic valve replacement in severe aortic stenosis: a longitudinal study of echocardiography parameters in cohort A of the PARTNER trial (Placement of Aortic Transcatheter Valves). J Am Coll Cardiol. 2013;61:2514-2521.

17. Reynolds MR, Magnuson EA, Lei Y, et al. Cost-effectiveness of transcatheter aortic valve replacement compared with surgical aortic valve replacement in high-risk patients with severe aortic stenosis: results of the PARTNER (Placement of Aortic Transcatheter Valves) trial (Cohort A). J Am Coll Cardiol. 2012;60:2683-2692.

18. Nielsen $\mathrm{HH}$, Klaaborg KE, Nissen $\mathrm{H}$, et al. A prospective, randomised trial of transapical transcatheter aortic valve implantation vs surgical aortic valve replacement in operable elderly patients with aortic stenosis: the STACCATO trial. EuroIntervention. 2012;8:383-389.

19. Popma JJ, Adams DH, Reardon MJ, et al. Transcatheter aortic valve replacement using a self-expanding bioprosthesis in patients with severe aortic stenosis at extreme risk for surgery. J Am Coll Cardiol. 2014;63:1972-1981.

20. Adams DH, Popma JJ, Reardon MJ, et al. Transcatheter aorticvalve replacement with a self-expanding prosthesis. $N$ Engl J Med. 2014;370:1790-1798.

21. Thomas M, Schymik G, Walther T, et al. One-year outcomes of cohort 1 in the Edwards SAPIEN Aortic Bioprosthesis European Outcome (SOURCE) registry: the European registry of transcatheter aortic valve implantation using the Edwards SAPIEN valve. Circulation. 2011;124:425-433.

22. Moat NE, Ludman P, de Belder MA, et al. Long-term outcomes after transcatheter aortic valve implantation in high-risk patients with severe aortic stenosis: the UK TAVI (United Kingdom Transcatheter Aortic Valve Implantation) Registry. J Am Coll Cardiol. 2011;58: 2130-2138.

23. Gilard M, Eltchaninoff H, Iung B, et al. Registry of transcatheter aortic-valve implantation in high-risk patients. $N$ Engl $\mathrm{J} \mathrm{Med}$. 2012;366:1705-1715.

24. Di Mario C, Eltchaninoff E, Moat N, et al. The 2011-2012 pilot European Sentinel Registry of transcatheter aortic valve implantation: in-hospital results in 4,571 patients. EuroIntervention. 2013;8: 1362-1371.

25. Rodés-Cabau J, Webb JG, Cheung A, et al. Long-term outcomes after transcatheter aortic valve implantation: insights on prognostic factors and valve durability from the Canadian multicenter experience. $J \mathrm{Am}$ Coll Cardiol. 2012;60:1864-1875. 
26. Toggweiler S, Humphries KH, Lee M, et al. 5-year outcome after transcatheter aortic valve implantation. J Am Coll Cardiol. 2013;61: 413-419.

27. Wood S. TAVI Registry Updates ADVANCE the field, raise hopes for lower stroke rates. Available from: http://www.medscape.com/viewarticle/760879. Accessed June 6, 2014.

28. Rodes-Cabau J, Webb JG, Cheung A, et al. Transcatheter aortic valve implantation for the treatment of severe symptomatic aortic stenosis in patients at very high or prohibitive surgical risk: acute and late outcomes of the multicenter Canadian experience. J Am Coll Cardiol. 2010;55:1080-1090.

29. Lefevre T, Kappetein AP, Wolner E, et al. One year follow-up of the multi-centre European PARTNER transcatheter heart valve study. Eur Heart J. 2011;32:148-157.

30. Thomas M, Schymik G, Walther T, et al. Thirty-day results of the SAPIEN aortic Bioprosthesis European Outcome (SOURCE) Registry: a European registry of transcatheter aortic valve implantation using the Edwards SAPIEN valve. Circulation. 2010;122:62-69.

31. Bosmans JM, Kefer J, De Bruyne B, et al. Procedural, 30-day and one year outcome following CoreValve or Edwards transcatheter aortic valve implantation: results of the Belgian national registry. Interact Cardiovasc Thorac Surg. 2011;12:762-767.

32. Eltchaninoff H, Prat A, Gilard M, et al. Transcatheter aortic valve implantation: early results of the FRANCE (FRench Aortic National CoreValve and Edwards) registry. Eur Heart J. 2011;32: 191-197.

33. Himbert D, Descoutures F, Al-Attar N, et al. Results of transfemoral or transapical aortic valve implantation following a uniform assessment in high-risk patients with aortic stenosis. J Am Coll Cardiol. 2009;54:303-311.

34. Walters DL, Sinhal A, Baron D, et al. Initial experience with the balloon expandable Edwards-SAPIEN Transcatheter Heart Valve in Australia and New Zealand: the SOURCE ANZ registry: outcomes at 30 days and one year. Int $J$ Cardiol. 2014;170:406-412.

35. Mack MJ, Brennan JM, Brindis R, et al. Outcomes following transcatheter aortic valve replacement in the United States. JAMA. 2013;310:2069-2077.

36. Svensson LG, Dewey T, Kapadia S, et al. United States feasibility study of transcatheter insertion of a stented aortic valve by the left ventricular apex. Ann Thorac Surg. 2008;86:46-54.

37. D'Onofrio A, Rubino P, Fusari M, et al. Clinical and hemodynamic outcomes of "all-comers" undergoing transapical aortic valve implantation: results from the Italian Registry of Trans-Apical Aortic Valve Implantation (I-TA). J Thorac Cardiovasc Surg. 2011;142:768-775.

38. Grube E, Schuler G, Buellesfeld L, et al. Percutaneous aortic valve replacement for severe aortic stenosis in high-risk patients using the second- and current third-generation self-expanding CoreValve prosthesis: device success and 30-day clinical outcome. J Am Coll Cardiol. 2007;50:69-76.

39. Piazza N, Grube E, Gerckens U, et al. Procedural and 30-day outcomes following transcatheter aortic valve implantation using the third generation (18 Fr) corevalve revalving system: results from the multicentre, expanded evaluation registry 1-year following CE mark approval. EuroIntervention. 2008;4:242-249.

40. Petronio AS, De Carlo M, Bedogni F, et al. Safety and efficacy of the subclavian approach for transcatheter aortic valve implantation with the CoreValve revalving system. Circ Cardiovasc Interv. 2010;3:359-366.

41. Tamburino C, Capodanno D, Ramondo A, et al. Incidence and predictors of early and late mortality after transcatheter aortic valve implantation in 663 patients with severe aortic stenosis. Circulation. 2011;123:299-308.

42. Buellesfeld L, Gerckens U, Schuler G, et al. 2-year follow-up of patients undergoing transcatheter aortic valve implantation using a self-expanding valve prosthesis. J Am Coll Cardiol. 2011;57:1650-1657.

43. Zahn R, Gerckens U, Grube E, et al. Transcatheter aortic valve implantation: first results from a multi-centre real-world registry. Eur Heart J. 2011;32:198-204.
44. Shroyer AL, Coombs LP, Peterson ED, et al. The Society of Thoracic Surgeons: 30-day operative mortality and morbidity risk models. Ann Thorac Surg. 2003;75:1856-1864.

45. Vahanian A, Alfieri O, Andreotti F, et al. Guidelines on the management of valvular heart disease (version 2012): the Joint Task Force on the Management of Valvular Heart Disease of the European Society of Cardiology (ESC) and the European Association for Cardio-Thoracic Surgery (EACTS). Eur J Cardiothorac Surg. 2012;42:S1-S44.

46. Holmes DR Jr, Mack MJ, Kaul S, et al. 2012 ACCF/AATS/SCAI/sts expert consensus document on transcatheter aortic valve replacement. J Am Coll Cardiol. 2012;59:1200-1254.

47. Leon MB, Piazza N, Nikolsky E, et al. Standardized endpoint definitions for transcatheter aortic valve implantation clinical trials: a consensus report from the Valve Academic Research Consortium. Eur Heart J. 2011;32:205-217.

48. Kappetein AP, Head SJ, Genereux P, et al. Updated standardized endpoint definitions for transcatheter aortic valve implantation: the Valve Acdemic Research Consortium-2 consensus document. EuroIntervention. 2012;8:782-795.

49. Daneault B, Kirtane AJ, Kodali SK, et al. Stroke associated with surgical and transcatheter treatment of aortic stenosis: a comprehensive review. J Am Coll Cardiol. 2011;58:2143-2150.

50. Eggebrecht H, Schmermund A, Voigtlander T, Kahlert P, Erbel R, Mehta RH. Risk of stroke after transcatheter aortic valve implantation (TAVI): a meta-analysis of 10,037 published patients. EuroIntervention. 2012;8:129-138.

51. Ghanem A, Muller A, Nahle CP, et al. Risk and fate of cerebral embolism after transfemoral aortic valve implantation: a prospective pilot study with diffusion-weighted magnetic resonance imaging. $J \mathrm{Am}$ Coll Cardiol. 2010;55:1427-1432.

52. Kahlert P, Knipp SC, Schlamann M, et al. Silent and apparent cerebral ischemia after percutaneous transfemoral aortic valve implantation: a diffusion-weighted magnetic resonance imaging study. Circulation. 2010;121:870-878.

53. Rodés-Cabau J, Dumont E, Boone RH, et al. Cerebral embolism following transcatheter aortic valve implantation: comparison of transfemoral and transapical approaches. J Am Coll Cardiol. 2011;57:18-28.

54. Drews T, Pasic M, Buz S, et al. Transcranial Doppler sound detection of cerebral microembolism during transapical aortic valve implantation. Thorac Cardiovasc Surg. 2011;59:237-242.

55. Szeto WY, Augoustides JG, Desai ND, et al. Cerebral embolic exposure during transfemoral and transapical transcatheter aortic valve replacement. J Card Surg. 2011;26:348-354.

56. Miller DC, Blackstone EH, Mack MJ, et al. Transcatheter (TAVR) versus surgical (AVR) aortic valve replacement: occurrence, hazard, risk factors, and consequences of neurologic events in the PARTNER trial. J Thorac Cardiovasc Surg. 2012;143:832-843. e13.

57. Amat-Santos IJ, Rodes-Cabau J, Urena M, et al. Incidence, predictive factors, and prognostic value of new-onset atrial fibrillation following transcatheter aortic valve implantation. J Am Coll Cardiol. 2012;59:178-188

58. Nuis RJ, Van Mieghem NM, Schultz CJ, et al. Frequency and causes of stroke during or after transcatheter aortic valve implantation. Am J Cardiol. 2012;109:1637-1643.

59. Sponga S, Perron J, Dagenais F, et al. Impact of residual regurgitation after aortic valve replacement. Eur J Cardiothorac Surg. 2012;42:486-492.

60. Webb JG, Pasupati S, Humphries K, et al. Percutaneous transarterial aortic valve replacement in selected high-risk patients with aortic stenosis. Circulation. 2007;116:755-763.

61. Walther T, Simon P, Dewey T, et al. Transapical minimally invasive aortic valve implantation: multicenter experience. Circulation. 2007;116:I240-I245.

62. De Jaegere PP, Piazza N, Galema TW, et al. Early echocardiographic evaluation following percutaneous implantation with the selfexpanding CoreValve revalving system aortic valve bioprosthesis. EuroIntervention. 2008;4:351-357. 
63. Detaint D, Lepage L, Himbert D, et al. Determinants of significant paravalvular regurgitation after transcatheter aortic valve: implantation impact of device and annulus discongruence. JACC Cardiovasc Interv. 2009;2:821-827.

64. Buzzatti N, Maisano F, Latib A, et al. Computed tomography-based evaluation of aortic annulus, prosthesis size and impact on early residual aortic regurgitation after transcatheter aortic valve implantation. Eur J Cardiothorac Surg. 2013;43:43-50.

65. Schultz CJ, Tzikas A, Moelker A, et al. Correlates on MSCT of paravalvular aortic regurgitation after transcatheter aortic valve implantation using the Medtronic CoreValve prosthesis. Catheter Cardiovasc Interv. 2011;78:446-455.

66. Ewe SH, Ng AC, Schuijf JD, et al. Location and severity of aortic valve calcium and implications for aortic regurgitation after transcatheter aortic valve implantation. Am J Cardiol. 2011;108:1470-1477.

67. Haensig M, Lehmkuhl L, Rastan AJ, et al. Aortic valve calcium scoring is a predictor of significant paravalvular aortic insufficiency in transapical-aortic valve implantation. Eur J Cardiothorac Surg. 2012;41:1234-1240.

68. Block PC. Leaks and the "great ship" TAVI. Catheter Cardiovasc Interv. 2010;75:873-874.

69. Zoghbi W. Recommendations for evaluation of the severity of native valvular regurgitation with two-dimensional and doppler echocardiography. J Am Soc Echocardiogr. 2003;16:777-802.

70. Athappan G, Patvardhan E, Tuzcu EM, et al. Incidence, predictors, and outcomes of aortic regurgitation after transcatheter aortic valve replacement: meta-analysis and systematic review of literature. J Am Coll Cardiol. 2013;61:1585-1595.

71. Sutton JP 3rd, Ho SY, Anderson RH. The forgotten interleaflet triangles: a review of the surgical anatomy of the aortic valve. Ann Thorac Surg. 1995;59:419-427.

72. Jilaihawi H, Chakravarty T, Weiss RE, Fontana GP, Forrester J, Makkar RR. Meta-analysis of complications in aortic valve replacement: comparison of Medtronic-Corevalve, Edwards-Sapien and surgical aortic valve replacement in 8,536 patients. Catheter Cardiovasc Interv. 2012;80:128-138.

73. Piazza N, Onuma Y, Jesserun E, et al. Early and persistent intraventricular conduction abnormalities and requirements for pacemaking after percutaneous replacement of the aortic valve. JACC Cardiovasc Interv. 2008;1:310-316.

74. Fraccaro C, Buja G, Tarantini G, et al. Incidence, predictors, and outcome of conduction disorders after transcatheter selfexpandable aortic valve implantation. Am J Cardiol. 2011;107: 747-754.

75. Nazif TM, Williams MR, Hahn RT, et al. Clinical implications of new-onset left bundle branch block after transcatheter aortic valve replacement: analysis of the PARTNER experience. Eur Heart J. 2014;35(24):1599-1607.

76. Goldenberg G, Kusniec J, Kadmon E, et al. Pacemaker implantation after transcatheter aortic valve implantation. Am J Cardiol. 2013;112:1632-1634.

77. Genereux P, Webb JG, Svensson LG, et al. Vascular complications after transcatheter aortic valve replacement: insights from the PARTNER (Placement of AoRTic TraNscathetER Valve) trial. J Am Coll Cardiol. 2012;60:1043-1052.

78. Van Mieghem NM, Tchetche D, Chieffo A, et al. Incidence, predictors, and implications of access site complications with transfemoral transcatheter aortic valve implantation. Am J Cardiol. 2012;110 1361-1367.

79. Hayashida K, Lefevre T, Chevalier B, et al. Transfemoral aortic valve implantation new criteria to predict vascular complications. JACC Cardiovasc Interv. 2011;4:851-858.

80. Makkar RR, Jilaihawi H, Chakravarty T, et al. Determinants and outcomes of acute transcatheter valve-in-valve therapy or embolization a study of multiple valve implants in the US PARTNER trial (Placement of AoRTic TraNscathetER Valve Trial Edwards SAPIEN Transcatheter Heart Valve). J Am Coll Cardiol. 2013;62:418-430.
81. Tuzcu EM. Transcatheter aortic valve replacement malposition and embolization: innovation brings solutions also new challenges. Catheter Cardiovasc Interv. 2008;72:579-580.

82. Naber CK, Ghanem A, Abizaid AA. First-in-man use of a novel embolic protection device for patients undergoing transcatheter aortic valve implantation. EuroIntervention. 2012;8:43-50.

83. Mullen M. First report of the DEFLECT trial: a prospective single arm feasibility study to evaluate the safety and performance of the Keystone Heart Trigard embolic deflection device in patients undergoing TAVI. Presented at the EuroPCR meeting, Paris, France, May 21-24, 2013.

84. Rodes-Cabau J. Procedural and early neurological outcomes in the PROTAVI-C pilot study. Presented at the EuroPCR meeting, Paris, France, May 21-24, 2013.

85. Grube E, Naber C, Abizaid A, Buellesfeld L. Feasibility of transcatheter aortic valve implantation without balloon pre-dilation: a pilot study JACC Cardiovasc Interv. 2011;4:751-757.

86. Noble S, Asgar A, Cartier R, Virmani R, Bonan R. Anatomopathological analysis after CoreValve Revalving system implantation. EuroIntervention. 2009;5:78-85.

87. Kini AS, Theodoropoulos K, Yu J, et al. Impact of Bivalirudin on access and non-access related bleeding in patients undergoing BAV (BRAVO) J Am Coll Cardiol. 2012;59:E266.

88. Van Belle E, Juthier F, Vincentelli A, et al. Can the use of a direct thrombin inhibitor prevent the risk of brain emboli during TAVI procedures? Eur Heart J. 2013;34 (Suppl 1).

89. Jabbour A, Ismail TF, Moat N, et al. Multimodality imaging in transcatheter aortic valve implantation and post-procedural aortic regurgitation comparison among cardiovascular magnetic resonance, cardiac computed tomography, and echocardiography. J Am Coll Cardiol. 2011;58:2165-2173.

90. Jilaihawi H, Kashif M, Fontana G, et al. Cross-sectional computed tomographic assessment improves accuracy of aortic annular sizing for transcatheter aortic valve replacement and reduces the incidence of paravalvular aortic regurgitation. J Am Coll Cardiol. 2012;59:1275-1286.

91. Willson AB, Webb JG, Labounty TM, et al. 3-dimensional aortic annular assessment by multidetector computed tomography predicts moderate or severe paravalvular regurgitation after transcatheter aortic valve replacement: a multicenter retrospective analysis. J Am Coll Cardiol. 2012;59:1287-1294.

92. Husser O, Rauch S, Endemann DH, et al. Impact of three-dimensional transesophageal echocardiography on prosthesis sizing for transcatheter aortic valve implantation. Catheter Cardiovasc Interv. 2012;80: 956-963.

93. Tamborini G, Fusini L, Gripari P, Muratori M, Pepi M. Feasibility and accuracy of 3D TEE versus CT for the evaluation of aortic valve annulus to the left main ostium distance before transcatheter aortic valve implantation. JACC Cardiovasc Imaging. 2012;5:579-588.

94. Sherif MA, Abdel-Wahab M, Stocker B, et al. Anatomic and procedural predictors of paravalvular aortic regurgitation after implantation of the Metronic CoreValve bioprosthesis. J Am Coll Cardiol. 2010;56: 1623-1629.

95. Jilaihawi H, Chin D, Spyt T, et al. Prosthesis-patient mismatch after transcatheter aortic valve implantation with the Medtronic-Corevalve bioprosthesis. Eur Heart J. 2010;31:857-864.

96. Binder RK, Leipsic J, Wood D, et al. Prediction of optimal deployment projection for transcatheter aortic valve replacement: angiographic 3-dimensional reconstruction of the aortic root versus multidetector computed tomography. Circ Cardiovasc Interv. 2012;5:247-252.

97. Poon KK, Crowhurst J, James C, et al. Impact of optimising fluoroscopic implant angles on paravalvular regurgitation in transcatheter aortic valve replacements - utility of three-dimensional rotational angiography. EuroIntervention. 2012;8:538-545.

98. Sinning JM, Hammerstingl C, Vasa-Nicotera M, et al. Aortic regurgitation index defines severity of peri-prosthetic regurgitation and predicts outcome in patients after transcatheter aortic valve implantation. J Am Coll Cardiol. 2012;59:1134-1141. 
99. Eggebrecht H, Doss M, Schmermund A, Nowak B, Krissel J, Voigtlander T. Interventional options for severe aortic regurgitation after transcatheter aortic valve implantation: balloons, snares, valvein-valve. Clin Res Cardiol. 2012;101:503-507.

100. Nombela-Franco L, Rodes-Cabau J, DeLarochelliere R, et al. Predictive factors, efficacy, and safety of balloon post-dilation after transcatheter aortic valve implantation with a balloon-expandable valve. JACC Cardiovasc Interv. 2012;5:499-512.

101. Vavuranakis M, Vrachatis DA, Toutouzas KP, Chrysohoou C, Stefanadis C. "Bail out" procedures for malpositioning of aortic valve prosthesis (CoreValve). Int J Cardiol. 2010;145:154-155.

102. Latib A, Michev I, Laborde JC, Montorfano M, Colombo A. Post-implantation repositioning of the CoreValve percutaneous aortic valve. JACC Cardiovasc Interv. 2010;3:119-121.

103. Piazza N, Schultz C, De Jaegere PT, Serruys PW. Implantation of two self-expanding aortic bioprosthesis valves during the same procedure? Insight into valve-in-valve implantation ("Russian doll" concept). Catheter Cardiovasc Interv. 2009;73:530-539.

104. Ussia GP, Barbanti M, Ramondo A, et al. The valve-in-valve technique for treatment of aortic bioprosthesis malposition an analysis of incidence and 1-year clinical outcomes from the italian CoreValve registry. J Am Coll Cardiol. 2011;57:1062-1068.

105. Toggweiler S, Wood DA, Rodes-Cabau J, et al. Transcatheter valve-invalve implantation for failed balloon-expandable transcatheter aortic valves. JACC Cardiovasc Interv. 2012;5:571-577.

106. Estevez-Loureiro R, Salgado-Fernandez J, Vazquez-Gonzalez N. Percutaneous closure of paravalvular leaks after transcatheter aortic valve implantation with Edwards SAPIEN prosthesis: a report of two cases. J Invasive Cardiol. 2013;25:92-95.

107. Poliacikova P, Hildick-Smith D. Paravalvular leak closure for persisting aortic regurgitation after implantation of the corevalve transcatheter valve. Catheter Cardiovasc Interv. October 15, 2013. [Epub ahead of print.]

108. Raffa GM, Malvindi PG, Settepani F, et al. Aortic valve replacement for paraprosthetic leak after transcatheter implantation. J Card Surg. 2012;27:47-51.

109. Ferreira ND, Caeiro D, Adao L, et al. Incidence and predictors of permanent pacemaker requirement after transcatheter aortic valve implantation with a self-expanding bioprosthesis. Pacing Clin Electrophysiol. 2010;33:1364-1372.

110. Erkapic D, De Rosa S, Kelava A, Lehmann R, Fichtlscherer S, Hohnloser SH. Risk for permanent pacemaker after transcatheter aortic valve implantation: a comprehensive analysis of the literature. J Cardiovasc Electrophysiol. 2012;23:391-397.

111. Mussardo M, Latib A, Chieffo A et al. Periprocedural and short-term outcomes of transfemoral transcatheter aortic valve implantation with the Sapien XT as compared with the Edwards Sapien valve. JACC Cardiovasc Interv. 2011;4:743-750.

112. Leon MB. A Randomized evaluation of the SAPIEN XT transcatheter valve system in patients with aortic stenosis who are not candidates for surgery: PARTNER II, inoperable cohort. American College of Cardiology Scientific Sessions San Francisco, CA 2013. Available from: http://www.cardiosource.org/ /media/Files/ScienceandQuality/ ClinicalTrials/ACC13Slides/PARTNERIIPresentationSlides.ashx. Accessed June 6, 2014.

113. Dimitriadis Z, Scholtz W, Faber L, et al. Balloon expandable sheath for transfemoral aortic valve implantation: a viable option for patients with challenging access. J Interv Cardiol. 2013;26: 84-89.

114. Toggweiler S, Gurvitch R, Leipsic J, et al. Percutaneous aortic valve replacement: vascular outcomes with a fully percutaneous procedure. J Am Coll Cardiol. 2012;59:113-118.

115. Toggweiler S, Leipsic J, Binder RK, et al. Management of vascular access in transcatheter aortic valve replacement: part 1: basic anatomy, imaging, sheaths, wires, and access routes. JACC Cardiovasc Interv. 2013;6:643-653.
116. Li X, Kong M, Jiang D, Dong A. Comparison 30-day clinical complications between transfemoral versus transapical aortic valve replacement for aortic stenosis: a meta-analysis review. J Cardiothorac Surg. 2013;8:168.

117. Petronio AS, De Carlo M, Bedogni F, et al. 2-year results of CoreValve implantation through the subclavian access: a propensitymatched comparison with the femoral access. J Am Coll Cardiol. 2012;60:502-507.

118. D’Onofrio A, Rizzoli G, Messina A, et al. Conventional surgery, sutureless valves, and transapical aortic valve replacement: what is the best option for patients with aortic valve stenosis? A multicenter, propensity-matched analysis. J Thorac Cardiovasc Surg. 2013;146: 1065-1070.

119. Tommaso CL, Bolman RM 3rd, Feldman T, et al. Multisociety (AATS, ACCF, SCAI, and STS) expert consensus statement: operator and institutional requirements for transcatheter valve repair and replacement, part 1: transcatheter aortic valve replacement. J Thorac Cardiovasc Surg. 2012;143:1254-1263.

120. Bourantas CV, Van Mieghem NM, Soliman O, Campos CA, Iqbal J, Serruys PW. Transcatheter aortic valve update 2013. EuroIntervention. 2013;9 Suppl:S84-S90.

121. Gooley R, Antonis P, Meredith IT. The next era of transcatheter aortic valve replacement: a case illustrating the benefit of a fully re-positionable, re-sheathable and retrievable prosthesis. Catheter Cardiovasc Interv. 2014;83:831-835.

122. Binder RK, Rodes-Cabau J, Wood DA, Webb JG. Edwards SAPIEN 3 valve. EuroIntervention. 2012;8 Suppl Q:Q83-Q87.

123. Kempfert J, Mollmann H, Walther T. Symetis ACURATE TA valve. EuroIntervention. 2012;8 Suppl Q:Q102-Q109.

124. Schofer J, Colombo A, Klugmann S, et al. Prospective multicenter evaluation of the direct flow medical transcatheter aortic valve. $J \mathrm{Am}$ Coll Cardiol. 2014;63:763-768.

125. Roy DA, Schaefer U, Guetta V, et al. Transcatheter aortic valve implantation for pure severe native aortic valve regurgitation. $J \mathrm{Am}$ Coll Cardiol. 2013;61:1577-1584.

126. Seiffert M, Diemert P, Koschyk D, et al. Transapical implantation of a second-generation transcatheter heart valve in patients with noncalcified aortic regurgitation. JACC Cardiovasc Interv. 2013;6:590-597.

127. Barbanti M, Ye J, Pasupati S, El-Gamel A, Webb JG. The Helio transcatheter aortic dock for patients with aortic regurgitation. EuroIntervention. 2013;9 Suppl:S91-S94.

128. Gao G, Wu Y, Grunkemeier GL, Furnary AP, Starr A. Durability of pericardial versus porcine aortic valves. $\mathrm{J} \mathrm{Am} \mathrm{Coll} \mathrm{Cardiol.}$ 2004;44:384-388.

129. Balsam LB, Grossi EA, Greenhouse DG, et al. Reoperative valve surgery in the elderly: predictors of risk and long-term survival. Ann Thorac Surg. 2010;90:1195-1200.

130. Dvir D, Webb J, Brecker S, et al. Transcatheter aortic valve replacement for degenerative bioprosthetic surgical valves: results from the global valve-in-valve registry. Circulation. 2012;126:2335-2344.

131. Gurvitch R, Cheung A, Ye J, et al. Transcatheter valve-in-valve implantation for failed surgical bioprosthetic valves. $\mathrm{J} \mathrm{Am} \mathrm{Coll}$ Cardiol. 2011;58:2196-2209.

132. Webb JG, Dvir D. Transcatheter aortic valve replacement for bioprosthetic aortic valve failure: the valve-in-valve procedure. Circulation. 2013;127:2542-2550.

133. Cheung AW, Gurvitch R, Ye J, et al. Transcatheter transapical mitral valve-in-valve implantations for a failed bioprosthesis: a case series. J Thorac Cardiovasc Surg. 2011;141:711-715.

134. Wilbring M, Alexiou K, Tugtekin SM, et al. Pushing the limits-further evolutions of transcatheter valve procedures in the mitral position, including valve-in-valve, valve-in-ring, and valve-in-native-ring. J Thorac Cardiovasc Surg. 2014;147:210-219.

135. Calvert PA, Himbert D, Brochet E, et al. Transfemoral implantation of an Edwards SAPIEN valve in a tricuspid bioprosthesis without fluoroscopic landmarks. EuroIntervention. 2012;7:1336-1339. 
136. Mazzitelli D, Bleiziffer S, Noebauer C, et al. Transatrial antegrade approach for double mitral and tricuspid "valve-in-ring" implantation. Ann Thorac Surg. 2013;95:e25-e27.

137. Himbert D, Pontnau F, Messika-Zeitoun D, et al. Feasibility and outcomes of transcatheter aortic valve implantation in high-risk patients with stenotic bicuspid aortic valves. Am J Cardiol. 2012;110:877-883.
138. Généreux P, Head SJ, Wood DA, et al. Transcatheter aortic valve implantation 10-year anniversary: review of current evidence and clinical implications. Eur Heart J. 2012;33(19):2388-2398.

Research Reports in Clinical Cardiology

Dovepress

\section{Publish your work in this journal}

Research Reports in Clinical Cardiology is an international, peerreviewed, open access journal publishing original research, reports, editorials, reviews and commentaries on all areas of cardiology in the clinic and laboratory. The manuscript management system is completely online and includes a very quick and fair peer-review system.
Visit http://www.dovepress.com/testimonials.php to read real quotes from published authors.

\footnotetext{
Submit your manuscript here: http://www.dovepress.com/research-reports-in-clinical-cardiology-journal
} 